\title{
Proteasome inhibition can induce an autophagy- dependent apical activation of caspase-8
}

\author{
MA Laussmann ${ }^{1}$, E Passante ${ }^{1}$, H Düssmann ${ }^{1}$, JA Rauen ${ }^{1}$, ML Würstle ${ }^{1}$, ME Delgado ${ }^{1}$, M Devocelle ${ }^{2}$, JHM Prehn ${ }^{1}$ and M Rehm,1
}

Antiapoptotic Bcl-2 family proteins are often highly expressed in chemotherapy-resistant cancers and impair mitochondrial outer membrane permeabilisation (MOMP), an important requirement for caspase activation via the intrinsic apoptosis pathway. Interestingly, although Bcl-2 overexpression in HeLa cervical cancer cells abrogated caspase processing in response to intrinsic apoptosis induction by staurosporine, tunicamycin or etoposide, residual caspase processing was observed following proteasome inhibition by bortezomib ([(1R)-3-methyl-1-(\{(2S)-3-phenyl-2-[(pyrazin-2-ylcarbonyl)amino]propanoyl\}amino)butyl]boronic acid), epoxomicin ( $N$-acetyl- $N$-methyl-lisoleucyl-L-isoleucyl- $N$-[(1S)-3-methyl-1-[[(2R)-2-methyloxiranyl]carbonyl]butyl]-Lthreoninamide) or MG-132 ( $N$-(benzyloxycarbonyl)leucinylleucinylleucinal). Similar responses were found in Bcl-2-overexpressing H460 NSCLC cells and Bax/Bak-deficient mouse embyronic fibroblasts. Mild caspase processing resulted in low DEVDase activities, which were MOMP independent and persisted for long periods without evoking immediate cell death. Surprisingly, depletion of caspase-3 and experiments in caspase-7-depleted MCF-7-Bcl-2 cells indicated that the DEVDase activity did not originate from effector caspases. Instead, Fas-associated death domain (FADD)-dependent caspase-8 activation was the major contributor to the slow, incomplete substrate cleavage. Caspase-8 activation was independent of death ligands, but required the induction of autophagy and the presence of Atg5. Depletion of XIAP or addition of XIAP-antagonising peptides resulted in a switch towards efficient apoptosis execution, suggesting that the requirement for MOMP was bypassed by activating the caspase-8/caspase-3 axis. Combination treatments of proteasome inhibitors and XIAP antagonists therefore represent a promising strategy to eliminate highly resistant cancer cells, which overexpress antiapoptotic Bcl-2 family members. Cell Death and Differentiation (2011) 18, 1584-1597; doi:10.1038/cdd.2011.27; published online 1 April 2011

Proteasomal activity is essential for eliminating excess proteins and, by counteracting protein production, establishes steady-state protein levels. The selective and often well-timed degradation of regulatory proteins by the proteasome orchestrates and modulates multiple biological processes such as gene transcription, metabolism, cell cycle progression and differentiation. ${ }^{1-2}$ Prolonged proteasome inhibition induces stress responses that initiate apoptosis via the intrinsic pathway. This is exploited clinically in the treatment of multiple myeloma with the proteasome inhibitor bortezomib $([(1 R)-3-$ methyl-1-(\{(2S)-3-phenyl-2-[(pyrazin-2-ylcarbonyl)amino]propanoyl\}amino)butyl]boronic acid). Impaired proteasome activity results in the accumulation and/or transcriptional induction of BH3-only proteins such as Puma, Bim, Noxa or Bik. BH3-only proteins antagonise antiapoptotic Bcl-2 family members such as $\mathrm{Bcl}-2, \mathrm{Bcl}-\mathrm{xL}$ or $\mathrm{Mcl}-1$ and/or can activate the proapoptotic members Bax and Bak. ${ }^{3}$ Activated Bax and Bak form pores in the outer mitochondrial membrane, resulting in cytochrome $c$ and Smac/Diablo release from the intermembrane space into the cytosol. This results in caspase-9 activation, inhibition of inhibitor of apoptosis (IAP) proteins, and subsequent apoptosis execution by effector caspases. $^{3}$

Proteasome inhibitors can evoke synergistic cell killing in combinations with other drugs that induce the intrinsic apoptosis pathway, such as cisplatin, doxorubicin, paclitaxel or histone deacetylase inhibitors, ${ }^{4-7}$ as well as with death receptor ligands activating the extrinsic pathway, such as tumour necrosis factor-related apoptosis-inducing ligand (TRAIL) and Fas L. ${ }^{8-11}$ Although the molecular mechanisms bringing about the synergistic responses are still under investigation, evidence has accumulated that synergies may emanate from complementary sets of BH3-only proteins being induced or may result from more efficient formation of the death-inducing signalling complex (DISC) in response to death ligands.

Proteasome inhibition however may also promote more efficient apoptotic cell death through the stabilisation of proapoptotic proteins implicated in apoptosis execution. Following mitochondrial permeabilisation, cytosolic

${ }^{1}$ Department of Physiology and Medical Physics, Royal College of Surgeons in Ireland, Dublin, Ireland and ${ }^{2}$ Department of Pharmaceutical and Medicinal Chemistry, Centre for Synthesis and Chemical Biology, Royal College of Surgeons in Ireland, Dublin, Ireland

${ }^{*}$ Corresponding author: M Rehm, Department of Physiology and Medical Physics, Royal College of Surgeons in Ireland, RCSI York House, York Street, Dublin 2, Ireland. Tel: + 3531402 8563; Fax: + 3531402 2447; E-mail: mrehm@rcsi.ie

Keywords: apoptosis; caspase-8; proteasome; autophagy; Atg5; Förster resonance energy transfer

Abbreviations: 3-MA, 3-methyl adenine; bortezomib, [(1R)-3-methyl-1-(\{(2S)-3-phenyl-2-[(pyrazin-2-ylcarbonyl)amino]propanoyl\}amino)butyl]boronic acid; CFP, cyan

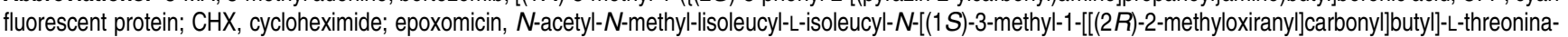
mide; FasL, fas ligand; FRET, Förster resonance energy transfer; MG-132, N-(benzyloxycarbonyl)leucinylleucinylleucinal; MOMP, mitochondrial outer membrane permeabilisation; PI, propidium iodide; IMS-RP, intermembrane space reporter protein; STS, staurosporine; TMRM, tetramethylrhodamine methylester; TNF- $\alpha$, tumour necrosis factor- $\alpha$; TRAIL, tumour necrosis factor-related apoptosis-inducing ligand; YFP, yellow fluorescent protein; zVAD, benzyloxycarbonyl-Val-Ala-Asp( $O$-methyl)fluoromethylketone

Received 08.9.10; revised 24.2.11; accepted 25.2.11; Edited by P Bouillet; published online 01.4.11 


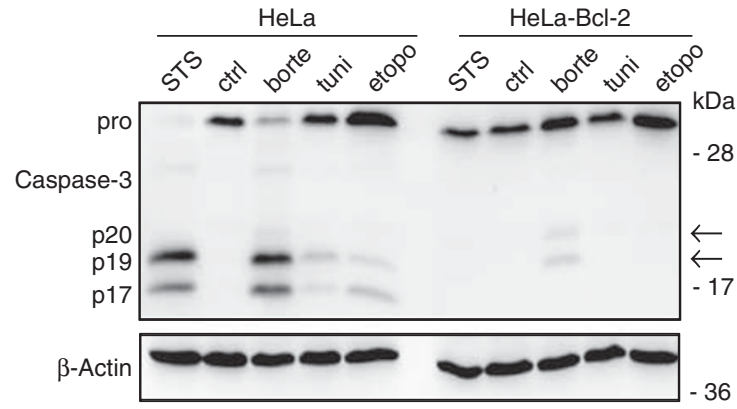

C
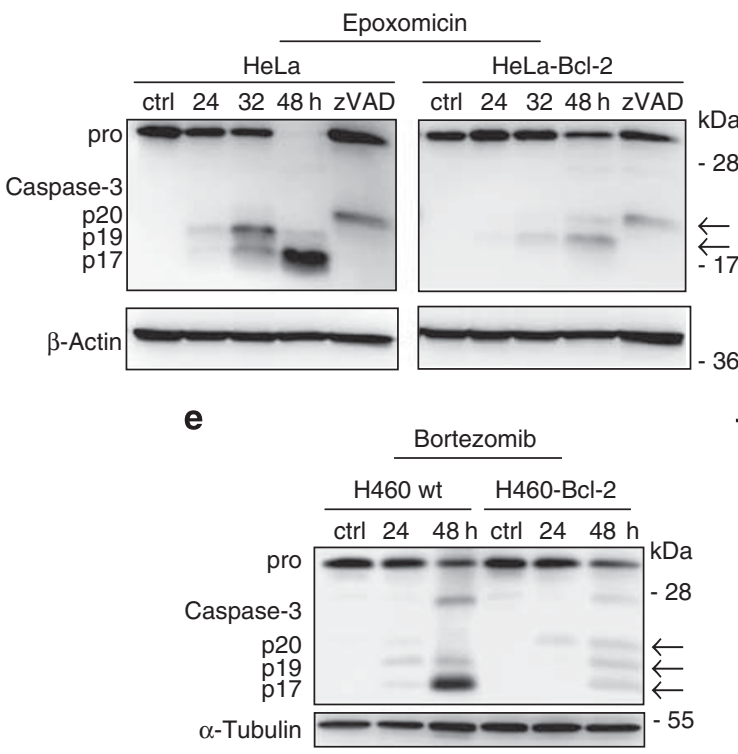

f b

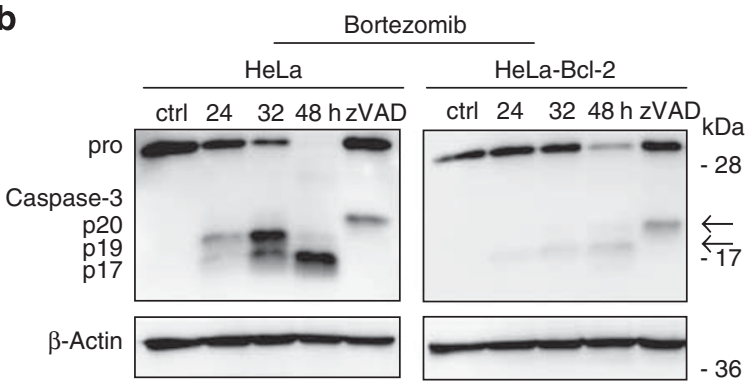

d HeLa-Bcl-2
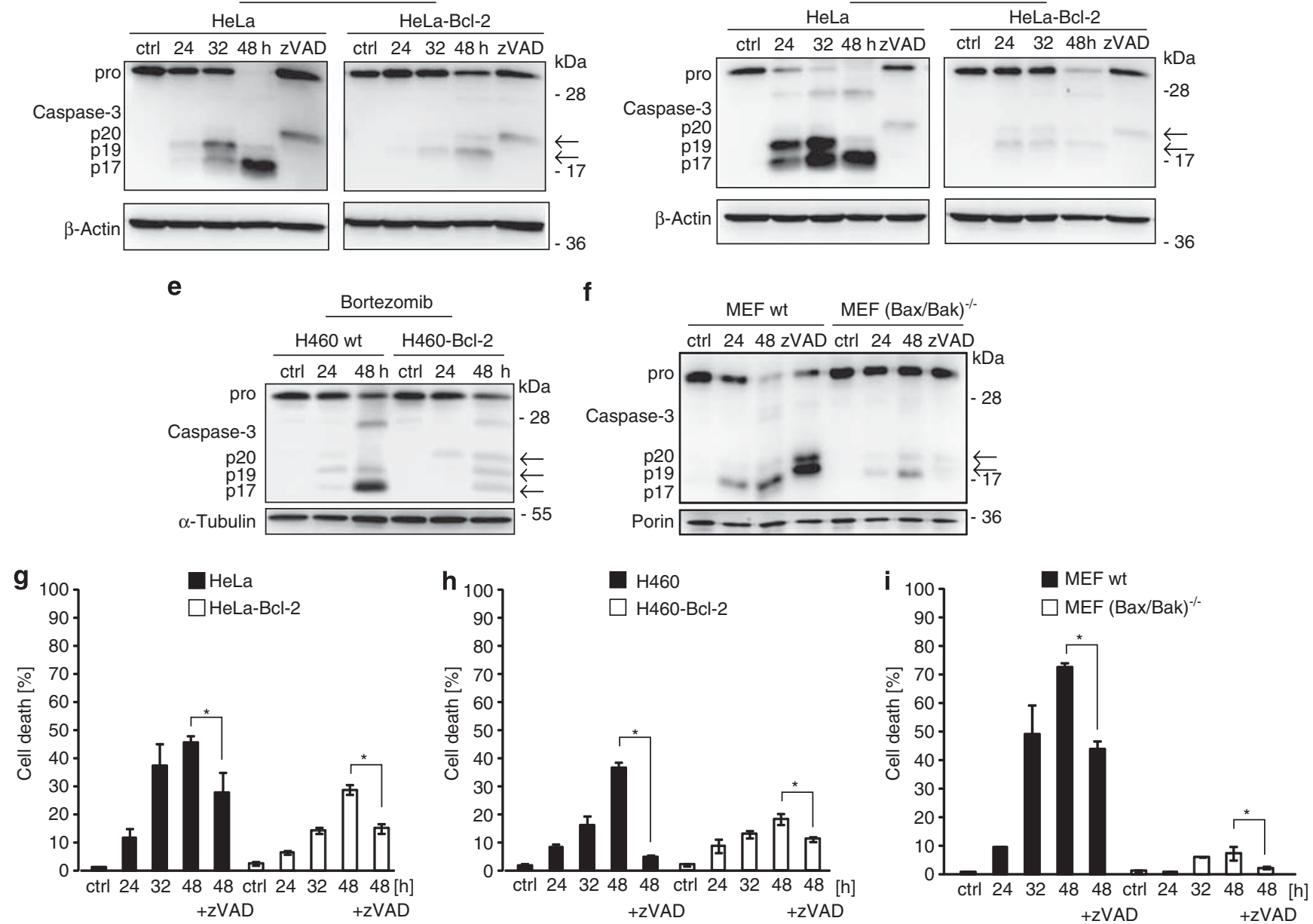

Figure 1 Proteasome inhibition promotes residual processing of procaspase-3 in cells expressing high levels of Bcl-2. (a) Proteasome inhibition induces residual procaspase-3 processing in Bcl-2-overexpressing HeLa cells. Parental and Bcl-2-overexpressing HeLa cells were compared by western blotting for processing of procaspase-3 in response to $1 \mu \mathrm{M}$ staurosporine (STS) $(8 \mathrm{~h}), 100 \mathrm{nM}$ bortezomib ([(1R)-3-methyl-1-(\{(2S)-3-phenyl-2-[(pyrazin-2-ylcarbonyl)amino]propanoyl\}amino)butyl]boronic acid) $(32 \mathrm{~h}), 3 \mu \mathrm{M}$ tunicamycin $(32 \mathrm{~h})$ or $10 \mu \mathrm{M}$ etoposide $(32 \mathrm{~h})$. Arrows indicate $\mathrm{p} 20$ and p19 caspase-3 subunits found in HeLa-Bcl-2 cells owing to residual procaspase-3 processing. Fully mature p17 subunits could not be detected in HeLa-Bcl-2 cells. $\beta$-Actin served as loading control. (b-d) Procaspase-3 processing in response to $100 \mathrm{nM}$ bortezomib, $50 \mathrm{nM}$ epoxomicin ( $N$-acetyl- $N$-methyl-lisoleucyl-L-isoleucyl- $N$-[(1S)-3-methyl-1-[(2R)-2-methyloxiranyl] $]$ carbonyl]butyl]-L-threoninamide) or $5 \mu \mathrm{M}$ MG-132 ( $N$-(benzyloxycarbonyl)leucinylleucinylleucinal) was compared between parental and Bcl-2-overexpressing HeLa cells. Although p20 and p19 subunits could be detected, fully mature caspase-3 (p17) was not detected in HeLa-Bcl-2 cells. Pan-caspase inhibitor benzyloxycarbonyl-Val-Ala-Asp(O-methyl)-fluoromethylketone (zVAD-fmk) (50 $\mu \mathrm{M})$ was used in combination with proteasome inhibitors in additional controls. $\beta$-Actin served as loading control. (e) Procaspase-3 processing in response to $100 \mathrm{nM}$ bortezomib was analysed in parental and Bcl-2-overexpressing $\mathrm{H} 460$ cells. Arrows indicate p20, p19 and p17 subunits. $\alpha$-Tubulin served as loading control. (f) As in (e), procaspase-3 processing in response to $100 \mathrm{nM}$ bortezomib was analysed in parental or Bax/Bak-deficient mouse embryonic fibroblasts. Porin served as loading control. (g-i) Cell death in response to $100 \mathrm{nM}$ bortezomib was determined by propidium iodide staining. Bcl-2 overexpression or Bax/Bak deficiency significantly reduced cell death. $z V A D$-fmk (50 $\mu \mathrm{M}$ ) was added in additional control groups. Data are shown as means \pm standard deviation (S.D.). Asterisks indicate significant reduction in cell death $(P<0.05$, Student's $t$-test). All experiments were preformed three times with comparable results 
Smac/Diablo and maybe also active caspases-9, -3 and -7 are subject to rapid IAP-mediated proteasomal degradation. ${ }^{12-13}$ Likewise, cytosolic cytochrome $c$ is swiftly degraded, but can be stabilised by proteasome inhibition. ${ }^{14}$ Here we investigated the consequences of proteasome inhibition on caspase activation and activity in human cancer cells. We show that in Bcl-2-overexpressing cancer cells refractory to mitochondrial permeabilisation, prolonged proteasome inhibition induced a mild, autophagy-dependent caspase- 8 activation, which, upon antagonising XIAP, can be exploited to eliminate $\mathrm{Bcl}-2$-overexpressing cells via the caspase-8/-3 axis.

\section{Results}

Proteasome inhibition promotes residual processing of procaspase-3 in cells expressing high levels of Bcl-2. We investigated apoptosis signalling in response to proteasome inhibition by analysing the conversion of the caspase-3 zymogen into active subunits. Processing of procaspase- 3 results in the generation of the small $p 12$ and large p20 active subunits, with the latter being further processed to the p19 and then to the p17 fragment by rapid and slow autocatalytic steps, respectively. ${ }^{15}$ Initially, we induced the intrinsic apoptosis pathway in HeLa cervical cancer cells by broad spectrum kinase inhibitor staurosporine (STS), N-glycosylation inhibitor tunicamycin, topoisomerase II inhibitor etoposide or proteasome inhibitor bortezomib. All drugs induced apoptosis execution, as noticed by procaspase-3 processing into the active caspase-3 p19/p17 subunits (Figure 1a). Particularly strong responses were observed upon STS and bortezomib treatment (Figure 1a). We then employed human cancer cells overexpressing Bcl-2 (Supplementary Figure 1) as model systems that are highly resistant to intrinsic apoptosis induction. Overexpression of $\mathrm{Bcl}-2$ in HeLa cells fully abrogated procaspase-3 processing in response to all drugs, except bortezomib, which still evoked residual and incomplete procaspase-3 processing (Figure 1a, arrows). Processing was attenuated at the p20/p19 subunits (Figure 1a, arrows), indicating that the slow autocatalytic step towards the p17 subunit was suppressed. ${ }^{15}$ Similar results were obtained when investigating other exposure durations or when employing proteasome inhibitors epoxomicin ( $N$-acetyl$N$-methyl-lisoleucyl-L-isoleucyl- $N$-[(1S)-3-methyl-1-[[(2R)-2methyloxiranyl]carbonyl]butyl]-L-threoninamide) or MG-132 ( $N$-(benzyloxycarbonyl)leucinylleucinylleucinal) (Figure 1b-d). Residual procaspase-3 processing was also observed in H460 non-small-cell lung cancer cells overexpressing Bcl-2 when exposed to bortezomib (Figure 1e), but not when incubated with STS (not shown), and in Bax/Bak doubledeficient mouse embryonic fibroblasts (MEFs) (Figure 1f). $\mathrm{Bcl}-2$ overexpression or Bax/Bak deficiency reduced bortezomib-induced cell death, and a further reduction was observed when adding pan-caspase inhibitor benzyloxycarbonyl-Val-Ala-Asp(O-methyl)-fluoromethylketone (zVADfmk) (Figure 1g-i). These results indicate that proteasome inhibition provokes a late and residual accumulation of incompletely processed caspase-3 as well as limited amounts of cell death in cells that otherwise seem refractory to intrinsic apoptosis. In the following, we therefore characterised the mode of caspase activation through proteasome inhibition in mitochondrial outer membrane permeabilisation (MOMP)-impaired cells. Owing to its high apoptotic potency (Figure 1a), we used STS in control groups as a model for classical MOMP-dependent apoptosis, but avoided treatment durations that result in secondary cell death arising from prolonged broad range kinase inhibition ${ }^{16}$ (Supplementary Figure 2).

Proteasome inhibition induces low levels of DEVDase activity in Bcl-2-overexpressing cells. To investigate whether the detected caspase processing resulted in any noticeable activity, we next measured DEVD substrate cleavage by Förster resonance energy transfer (FRET) disruption. ${ }^{17}$ In the FRET substrate, a caspase cleavage site (DEVD) links donor and acceptor fluorophores (cyan and yellow fluorescent protein (CFP, YFP)), and CFP fluorescence increases upon substrate cleavage (Figure 2a). The DEVD sequence is optimally cleaved by caspase- 3 and -7 , but can also be cleaved by initiator caspase-8. ${ }^{18}$ As the FRET probe is a soluble cytosolic protein, the analysis is restricted to non-permeabilised cells. In parental HeLa cells, bortezomib and STS resulted in FRET probe cleavage in nearly all cells (Figure $2 b$ ). In cells

\footnotetext{
Figure 2 Proteasome inhibition induces low levels of DEVDase activity in Bcl-2-overexpressing cells. (a) A cyan fluorescent protein (CFP)-DEVD-yellow fluorescent protein (YFP) Förster resonance energy transfer (FRET) probe was used to measure DEVDase activity in individual cells by flow cytometry. Cleavage of the probe by DEVDases results in a loss in FRET and a concomitant increase in CFP emission. (b) Flow cytometric analysis of parental HeLa cells expressing the DEVD FRET probe. Cells were treated for the indicated times with $100 \mathrm{nM}$ bortezomib ([(1R)-3-methyl-1-(\{(2S)-3-phenyl-2-[(pyrazin-2-ylcarbonyl)amino]propanoyl\}amino)butyl]boronic acid). Benzyloxycarbonyl-Val-Ala-Asp ( $O$-methyl)-fluoromethylketone (zVAD-fmk) co-treated controls ensured caspase specificity of the readout. For comparison, control groups treated with $1 \mu \mathrm{M}$ staurosporine (STS) (8h) are shown as well. Data are mean \pm standard deviation (S.D.) from $n=3$ experiments. Asterisks indicate significant increase in FRET probe cleavage above control groups $(P<0.05$; one-way analysis of variance (ANOVA) and subsequent Tukey's test). (c) Flow cytometric analysis of HeLa-Bcl-2 cells expressing the DEVD FRET probe. Cells were treated as in (b). Data are means \pm S.D. from $n=3$ experiments. Asterisks indicate significant increase in FRET probe cleavage above control groups ( $P<0.05$; one-way ANOVA and subsequent Tukey's test). (d) As described in (b and $\mathbf{c})$, DEVD FRET probe cleavage was analysed in wildtype and Bax/Bak-deficient mouse embryonic fibroblasts. (e) Scatter plots displaying DEVD FRET probe cleavage in parental HeLa cells. Treatment with $100 \mathrm{nM}$ bortezomib resulted in clearly separable populations of cells with intact or cleaved FRET probe. Caspase inhibition by ZVAD-fmk inhibited probe cleavage. (f) Scatter plots displaying DEVD FRET probe cleavage in HeLa-Bcl-2 cells. Following treatment with $100 \mathrm{nM}$ bortezomib populations of cells with intact or cleaved FRET probe were inseparable, indicating slow or incomplete substrate cleavage. Caspase inhibition by zVAD-fmk inhibited probe cleavage. $(\mathbf{g}$ and $\mathbf{h})$ Ratiometric analysis of FRET probe cleavage indicates that bortezomib-induced DEVDase activity in parental HeLa cells $(\mathbf{g})$ resulted in separated peaks of intact or cleaved probe. In comparison, probe cleavage was significantly reduced in HeLa-Bcl-2 cells (h), as indicated by a right-shift and reduction in peak height at $24 \mathrm{~h}$ and inseparable peaks at $48 \mathrm{~h}$ post-addition of $100 \mathrm{nM}$ bortezomib
} 
overexpressing $\mathrm{Bcl}-2$, FRET probe cleavage was detected in a small, but still substantial fraction of the bortezomib-treated cells (Figure 2c). zVAD-fmk addition potently inhibited probe cleavage and confirmed the caspase specificity of the readout. Similar responses were also detected in Bax/Bakdeficient MEFs (Figure 2d).

a
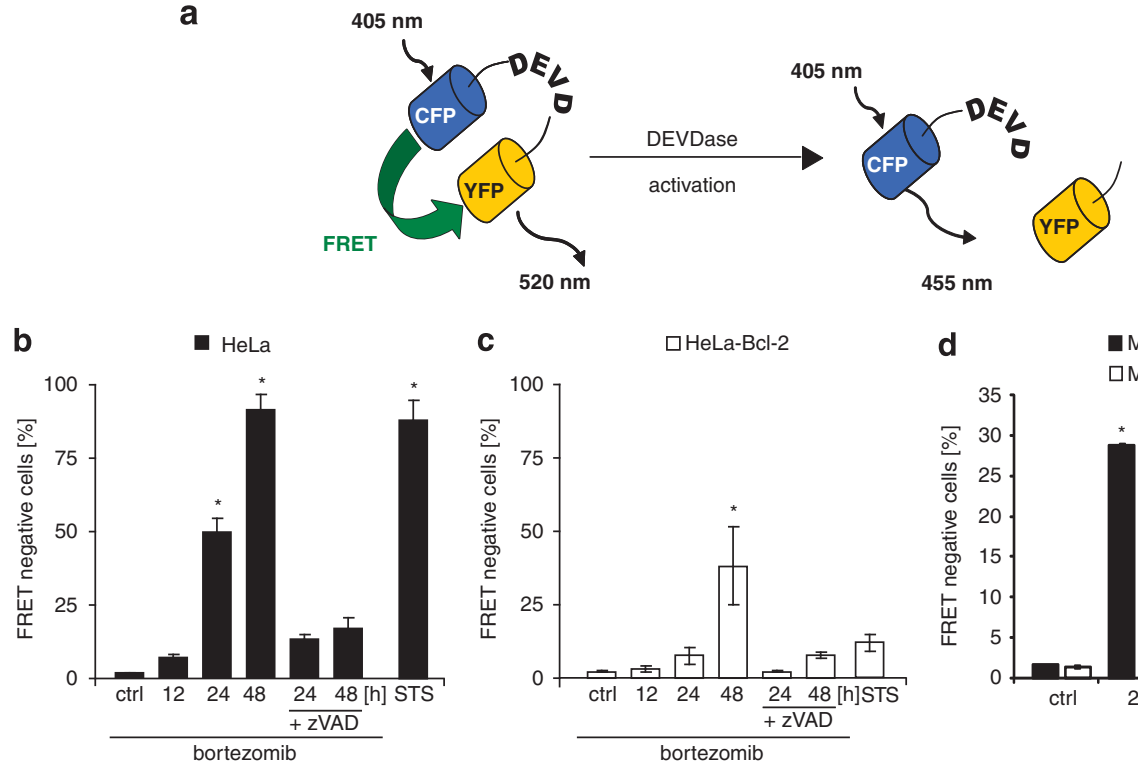

C

口HeLa-Bcl-2

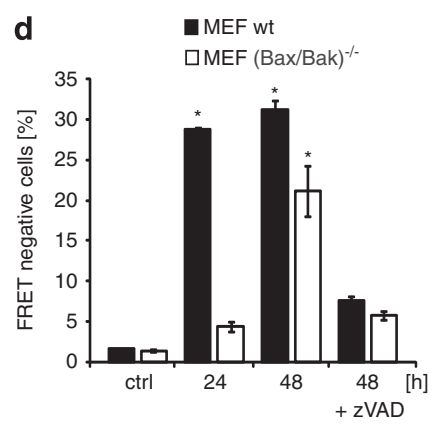

$\mathbf{e}$
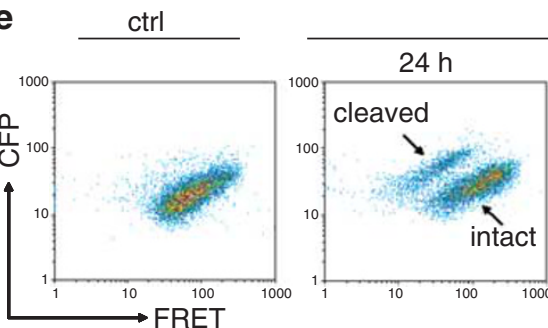

Bortezomib

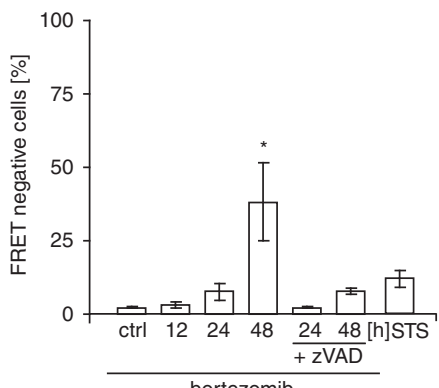

f
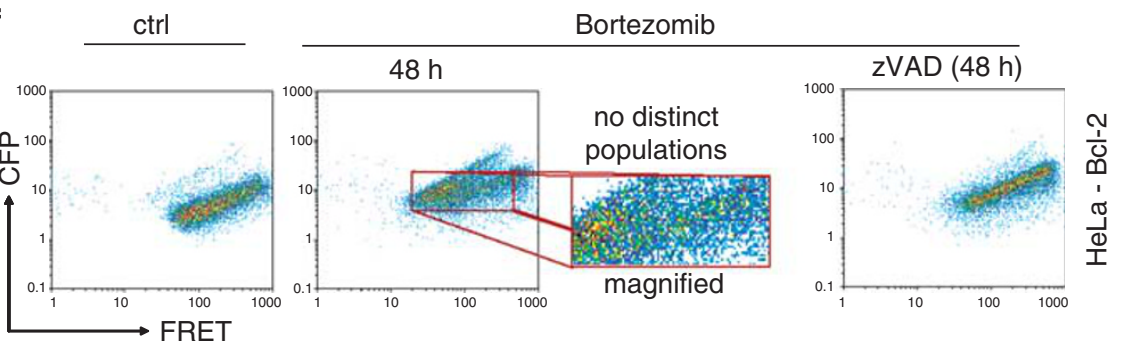

g

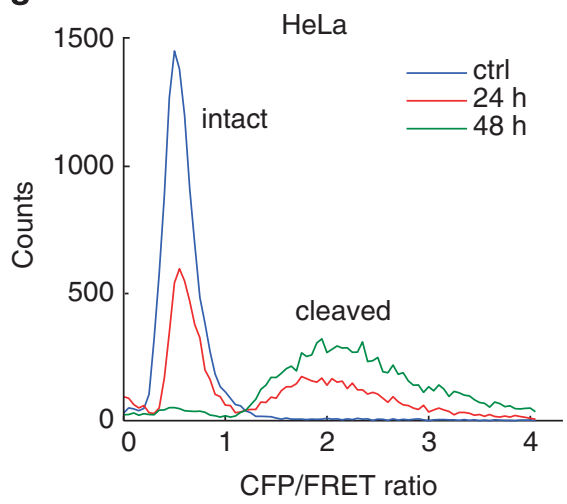

h

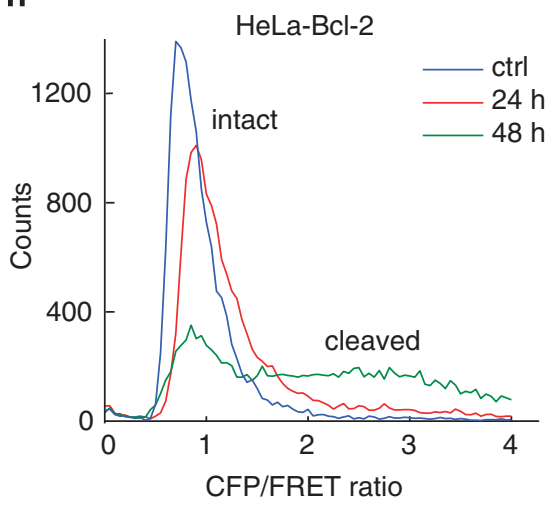


CFP vs FRET scatter plots obtained from bortezomibtreated samples indicated further differences between parental and Bcl-2 overexpressing HeLa cells (Figure 2e and f). In parental cells, populations with intact or cleaved FRET probe could be clearly separated (Figure $2 e$ ), indicative of a caspase-3-dependent rapid probe cleavage as described in response to other drugs previously. ${ }^{17}$ In contrast, scatter plots of HeLa-Bcl-2 cells showed a significant number of cells with submaximal probe cleavage, that is, they were positioned in-between populations with intact and cleaved probe (Figure 2f). A ratiometric CFP/FRET display likewise indicated that parental cells displayed with intact or cleaved probe, whereas in HeLa-Bcl-2 cells the two populations could not be separated (Figure $2 \mathrm{~g}$ and $\mathrm{h}$ ). These results therefore show that proteasome inhibition induces low DEVDase activities in cells that otherwise do not respond to intrinsic apoptosis initiation.

Time-lapse analysis of DEVDase activation and activity
induced by proteasome inhibition. We next employed FRET-based single-cell time-lapse imaging to determine the kinetics and timings of DEVDase activation. Most cells responded with DEVDase activation within $72 \mathrm{~h}$ of bortezomib addition, independent of $\mathrm{Bcl}-2$ overexpression (Figure 3a). However, DEVDase activity in HeLa Bcl-2 cells started later than in parental cells $(14 \pm 3.2 \mathrm{~h}$; mean \pm S.E.M.) (Figure 3b). Once initiated, probe cleavage proceeded rapidly in parental HeLa cells (14.7 $\pm 1.0 \mathrm{~min}$; mean \pm S.E.M.), indicating a swift activation of effector caspases (Figure 3c). Similar cleavage durations were measured in response to STS $(11.5 \pm 0.7 \mathrm{~min}$; mean \pm S.E.M.; $n=21$ cells analysed from three experiments), corresponding to previously published data. ${ }^{19}$ In contrast, probe cleavage in HeLa-Bcl-2 cells proceeded significantly slower (81.3 $\pm 13.4 \mathrm{~min}$; mean \pm S.E.M.) (Figure 3c). In many of these cells, the cleavage process might not have reached completion before termination of image acquisition as many cells detached and left the focal plane late during substrate cleavage. We therefore additionally determined the slopes of the FRET disruption traces to measure DEVDase activity, and found a significant reduction in HeLa-Bcl-2 cells (Figure $3 d$ ). Floating cells, analysed by western blotting for probe cleavage, provided additional evidence for submaximal substrate cleavage (Supplementary Figure 3).

We also loaded cells with tetramethylrhodamine-methylester (TMRM) to monitor changes in mitochondrial membrane potentials $\left(\Delta \Psi_{\mathrm{M}}\right)$. As $\Delta \Psi_{\mathrm{M}}$ rapidly drops upon cytochrome $c$ release at standard experimental conditions, TMRM was used as a surrogate marker for MOMP. As expected, in HeLa cells treated with STS, DEVDase activity was exclusively detected subsequent to $\Delta \Psi_{\mathrm{M}}$ depolarisation (3.2 \pm 0.4 min lag time; mean \pm S.E.M.), corresponding to earlier reports. ${ }^{19}$ Similarly, proteasome inhibition resulted in DEVDase activity subsequent to $\Delta \Psi_{\mathrm{M}}$ depolarisation in most cells (Figure $3 e$ ) (mean lag time $3.6 \pm 0.6$ min; mean \pm S.E.M.). Only a small subpopulation of HeLa cells (5 out of 32 cells) displayed DEVDase activity $5.6 \pm 3.6$ min (mean \pm S.E.M.) before $\Delta \Psi_{\mathrm{M}}$ loss. In HeLa-Bcl-2 cells instead DEVDase activation occurred nearly exclusively upstream of changes in $\Delta \Psi_{M}$ (Figure $3 f$ ) (20 out of 21 cells $=95 \%$ ), and activity persisted until cells left the focal plane or the image acquisition was terminated. To further validate this finding, we also observed MOMP more directly using cells expressing a red fluorescent mitochondrial intermembrane space protein (IMS-RP) in parallel to the FRET probe. In HeLa cells, IMS-RP release started shortly before DEVDases were activated (Figure $3 \mathrm{~g}$ ). In contrast, DEVDase activation in HeLa-Bcl-2 cells was detected nearly exclusively independent of IMS-RP release (14 out of 15 cells $=93 \%$ ) (Figure 3h). Also cell-endogenous caspase substrates were cleaved: the $120 \mathrm{kDa}$ cleavage fragment of $\alpha$-spectrin,

Figure 3 Time-lapse analysis of DEVDase activation and activity induced by proteasome inhibition. (a) Parental and Bcl-2-overexpressing cells were analysed for DEVDase activation in Förster resonance energy transfer (FRET) imaging experiments. The incidence of DEVDase activation following treatment with $100 \mathrm{nM}$ bortezomib ([(1R)-3-methyl-1-(\{(2S)-3-phenyl-2-[(pyrazin-2-ylcarbonyl)amino]propanoyl\}amino)butyl]boronic acid) was determined from the total number of cells analysed ( $n=43$ parental cells from four experiments and $n=27 \mathrm{Bcl}-2$-overexpressing cells from six experiments). DEVDase activation was evaluated as an irreversible increase of the cyan and yellow fluorescent protein (CFP/YFP) ratio signal above the baseline. Bcl-2 overexpression did not affect the frequency of DEVDase activation. (b) The time from bortezomib addition until activation of DEVDases was determined for all cells measured. DEVDase activity was detected later in Bcl-2-overexpressing cells. Asterisk indicates significant difference $(P<0.05, U$-test). (c) The duration of DEVD probe cleavage was determined for all cells analysed. Bcl-2 overexpression prolonged the duration of probe cleavage. Asterisk indicates significant difference $(P<0.05$, U-test). (d) The DEVDase activity was determined as the rate of probe cleavage (change in CFP/YFP emission over time) for all cells investigated. Overexpression of Bcl-2 strongly reduced the DEVDase activity determined in single living cells. Asterisk indicates significant difference $(P<0.05, U$-test). (e) DEVD FRET probe cleavage in parental HeLa cells. Traces of DEVD FRET probe cleavage are shown for four representative HeLa cells following exposure to $100 \mathrm{nM}$ bortezomib. FRET probe cleavage resulted in an increase in the CFP/YFP emission ratio. Onset of DEVDase activity was set to time zero. Tetramethylrhodamine-methylester (TMRM) fluorescence was plotted to indicate changes in mitochondrial membrane potentials. Mitochondrial depolarisation started shortly before DEVDase activation. Similar results were obtained from $n=23$ additional cells. (f) DEVD FRET probe cleavage in HeLa cells overexpressing Bcl-2. Experimental traces of DEVD FRET probe cleavage are shown for four representative HeLa-Bcl-2 cells following exposure to $100 \mathrm{nM}$ bortezomib. Onset of DEVDase activity was set to time zero. FRET probe cleavage displayed in increases in the CFP/YFP emission ratio that were lower and prolonged when compared with parental HeLa cells (e). In contrast to parental HeLa cells, changes in mitochondrial membrane potentials were not detectable at the time DEVDase activation was measured. Late changes in TMRM signals resulted from cells rounding up and detaching. Similar results were obtained for $n=12$ additional cells. (g) DEVD FRET probe cleavage in parental HeLa cells was observed in parallel with the release of red fluorescent protein (mCherry) from the mitochondrial intermembrane space (IMS-RP). The release of IMS-RP results in a fluorescence re-distribution towards a homogeneous signal across the cell (see also Materials and Methods section). The start of IMS-RP release was therefore defined as the time at which the cellular fluorescence standard deviation (S.D.) started to drop. IMS-RP release preceded DEVDase activation. Similar results were obtained from $n=5$ additional cells. (h) In HeLa cells overexpressing Bcl-2, DEVDase activation resulted in slow and prolonged substrate cleavage. No release of IMS-RP could be detected, indicating that DEVDase activity was established independent of membrane permeabilisation (MOMP). Similar results were obtained for $n=14$ cells. (i) $\alpha$-Spectrin cleavage after bortezomib treatment. Prolonged exposure to bortezomib resulted in the detection of the caspase-specific $120 \mathrm{kDa}$ cleavage product and loss of full-length $\alpha$-spectrin in parental cells, which was strongly diminished in HeLa cells overexpressing Bcl-2. $\alpha$-Tubulin served as loading control 
a substrate preferred by caspase-3, accumulated strongly in parental cells, whereas in HeLa-Bcl-2 cells, only a mild and late increase was detected (Figure 3i). These data therefore indicate that proteasome inhibition can result in a mild, submaximal activation of DEVDases independent of MOMP. a

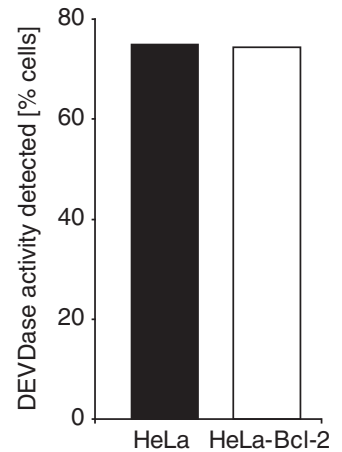

b

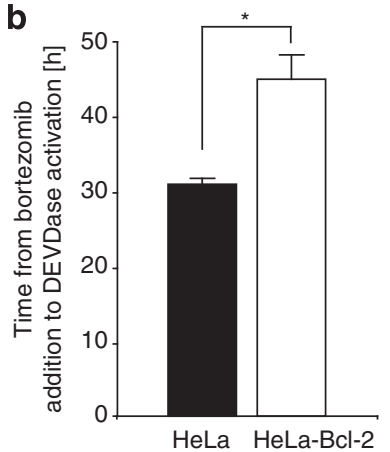

C

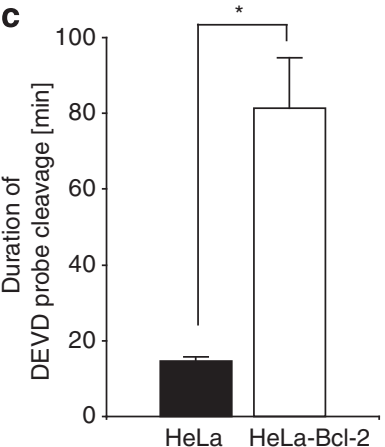

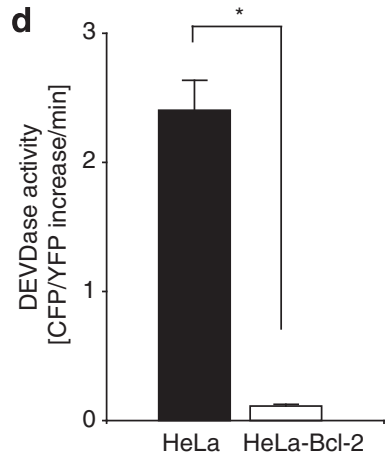

f

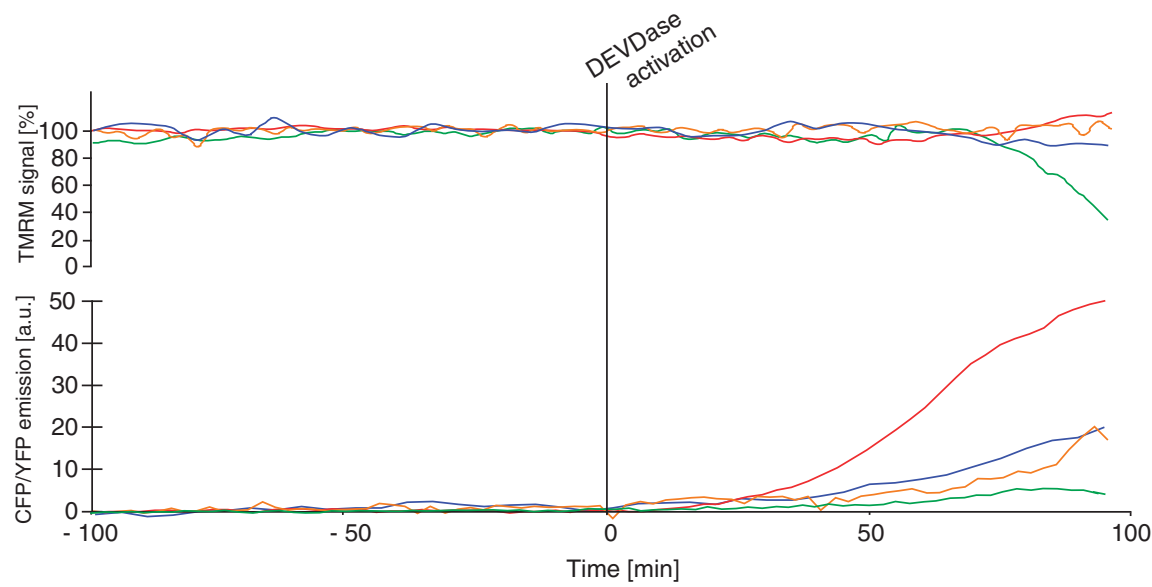

h
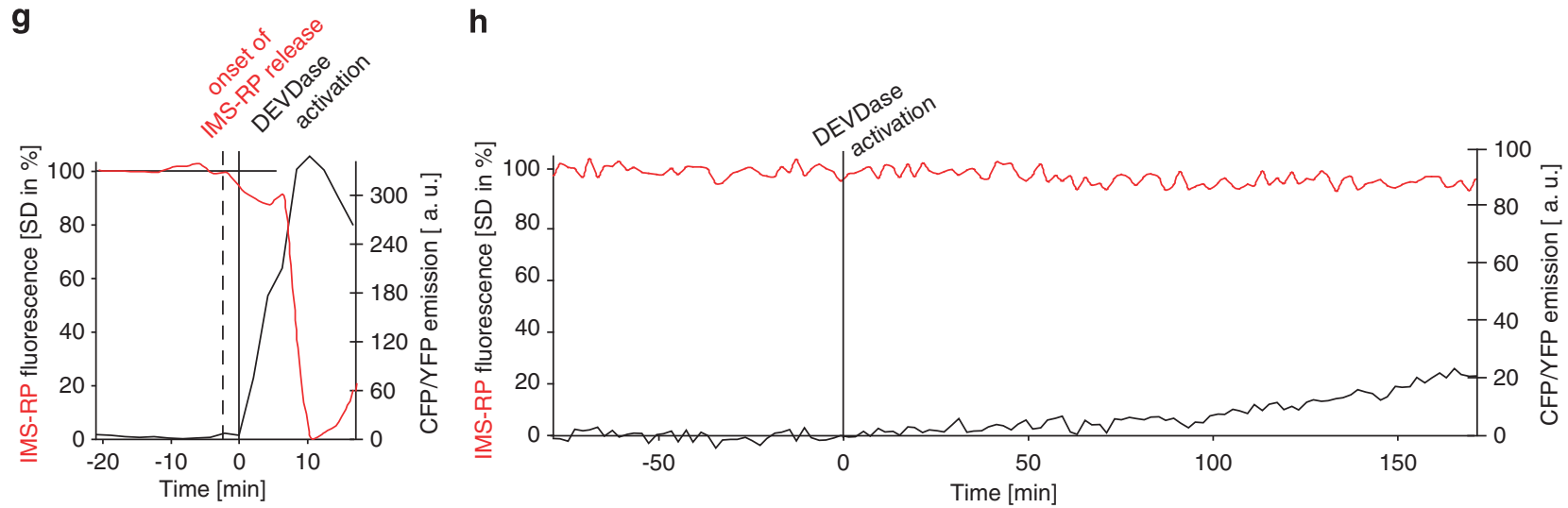

i

HeLa

HeLa-Bcl-2
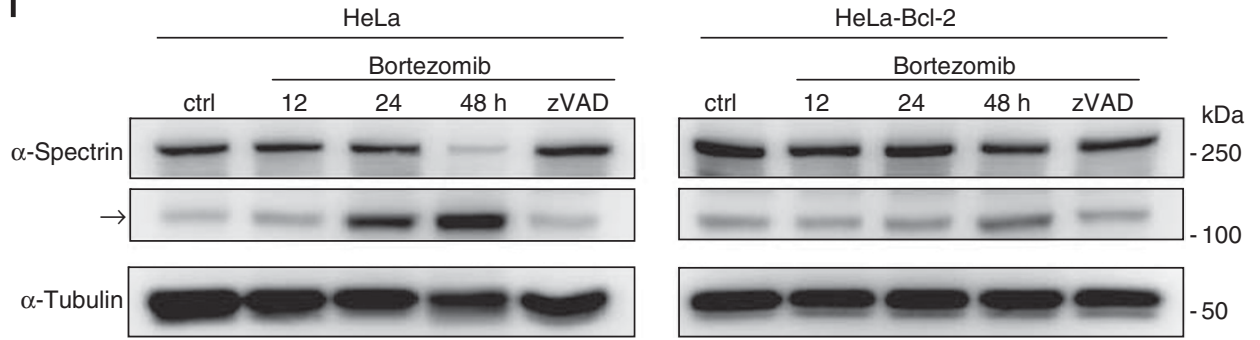
MOMP-independent DEVDase activity in response to proteasome inhibition does not arise from caspase-3 or -7. To identify which caspases contributed to DEVDase activity in response to proteasome inhibition, we employed
siRNA-mediated protein depletion. All siRNAs used were previously published to be specific for their respective targets (see Supplementary Material 1). siRNAs were co-transfected with pCFP-DEVD-YFP and the addition of bortezomib was

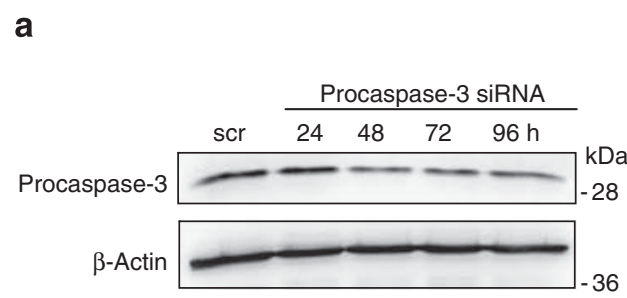

C

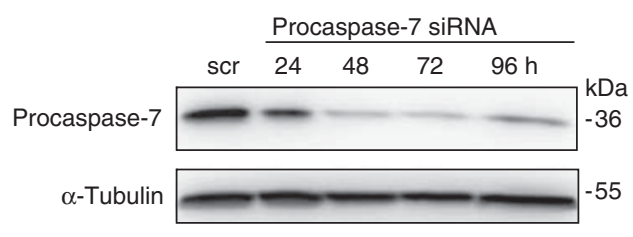

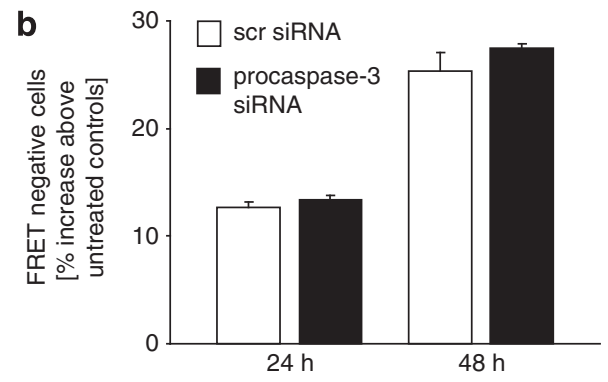

MCF-7-Bcl-2 d

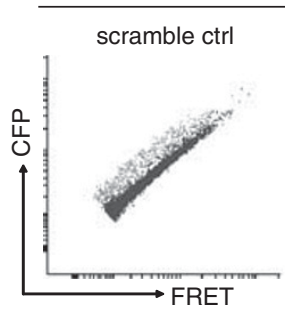

scramble Borte

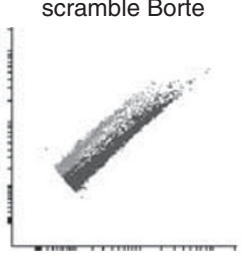

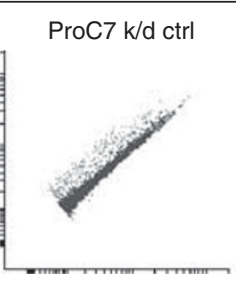

ProC7 k/d Borte

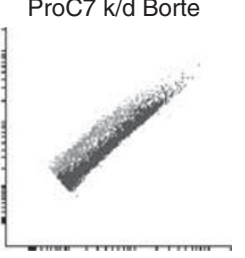

Figure 4 DEVDase activity in response to proteasome inhibition does not arise from caspase-3 or -7 activity. (a) Depletion of procaspase-3 by small interfering RNA (siRNA) transfection. HeLa-Bcl-2 cells were analysed for procaspase-3 expression at the indicated times following siRNA transfection. $\beta$-Actin served as loading control. A scrambled siRNA (scr) was transfected in control cells. (b) HeLa-Bcl-2 cells depleted of procaspase-3 expression were analysed for DEVD Förster resonance energy transfer (FRET) probe cleavage by flow cytometry following treatment with $100 \mathrm{nM}$ bortezomib ([(1R)-3-methyl-1-(\{(2S)-3-phenyl-2-[(pyrazin-2-ylcarbonyl)amino]propanoyl\}amino)butyl]boronic acid). siRNA transfection preceded drug addition by $24 \mathrm{~h}$ to provide efficient target depletion $24 \mathrm{~h}$ subsequent to bortezomib addition (see Supplementary Figure 8). Depletion of caspase-3 did not reduce FRET probe cleavage. Bars display changes in FRET substrate cleavage (\%) above untreated controls. Data represent mean \pm standard deviation (S.D.) from $n=9$ values obtained from bootstrap resampling of independent treatment and control triplicates. Experiment was repeated with similar results. (c) Depletion of procaspase-7 by siRNA transfection in Bcl-2-overexpressing MCF-7 cells. Cells were analysed for procaspase-7 expression at the indicated times following siRNA transfection. $\beta$-Actin served as loading control. Scrambled siRNA (scr) was transfected in control cells. (d) MCF-7-Bcl-2 cells depleted of procaspase-7 and expressing the DEVD FRET probe were exposed to $100 \mathrm{nM}$ bortezomib for $48 \mathrm{~h}$ and analysed by flow cytometry. siRNA transfection preceded drug addition by $48 \mathrm{~h}$ to provide efficient target depletion $24 \mathrm{~h}$ subsequent to bortezomib addition (see Supplementary Figure 8). A continuous spectrum of substrate cleavage, which could not be inhibited by procaspase-7 depletion, was detected. Experiment was repeated with similar results

Figure 5 DEVDase activity in response to proteasome inhibition arises from Fas-associated death domain (FADD)-dependent caspase-8 activation. (a) Time-resolved analysis of procaspase-8 processing into p43/41 and p18 subunits induced by $100 \mathrm{nM}$ bortezomib $([(1 R)-3-$ methyl-1- $(\{(2 S)-3-$ phenyl-2-[(pyrazin-2-ylcarbonyl)amino]propanoyl\}amino)butyl]boronic acid) in parental HeLa cells. Porin served as loading control. (b) As in (a), procaspase-8 processing was investigated in HeLa cells overexpressing $\mathrm{BCl}$-2. Procaspase-8 was only residually processed (arrows) and processing occurred at later times than in parental HeLa cells. Porin served as loading control. All experiments were preformed three times with comparable results. (c) Bid processing was observed by western blotting in whole-cell extract of HeLa or HeLa Bcl-2 cells treated with $100 \mathrm{nM}$ bortezomib for the indicated times. Corresponding to data on caspase-8 processing (a and $\mathbf{b})$, Bid cleavage in HeLa Bcl-2 cells was delayed. Arrow and high-contrast panel indicate truncated Bid. Porin served as loading control. (d) Depletion of caspase-8 by small interfering RNA (siRNA) transfection. HeLa-Bcl-2 cells were analysed for procaspase-8 expression at the indicated times following siRNA transfection. $\beta$-Actin served as loading control. A scrambled siRNA (scr) was transfected in control cells. (e) HeLa Bcl-2 cells depleted of procaspase-8 expression were analysed for DEVD Förster resonance energy transfer (FRET) probe cleavage by flow cytometry following treatment with $100 \mathrm{nM}$ bortezomib. siRNA transfection preceded drug addition by $24 \mathrm{~h}$ to provide efficient target depletion $24 \mathrm{~h}$ subsequent to bortezomib addition (see Supplementary Figure 8). Bars display changes in FRET substrate cleavage (\%) above untreated controls. Data represent mean \pm standard deviation (S.D.) from $n=9$ values obtained from bootstrap resampling of independent triplicates. Depletion of procaspase-8 significantly reduced FRET probe cleavage $(P<0.05$, U-test). Experiment was repeated with similar results. (f) Procaspase-8 depletion by siRNA delivery impairs DEVDase activation in HeLa Bcl-2 cells after exposure to bortezomib. After depletion of procaspase-3 or -8 , cells were analysed for DEVDase activation by time-lapse FRET imaging. Scrambled siRNA was transfected in control cells. Procaspase-8 depletion resulted in significantly less cells displaying DEVDase activity. Data are from $n=27$ (scr), 27 (procaspase-3) and 40 (procaspase-8) cells from three to four independent experiments per group. (g) Depletion of procaspase-8 reduced caspase-3 processing as evidenced by a lower conversion of procaspase-3 into p20/p19 subunits. HeLa Bcl-2 cells were treated with $100 \mathrm{nM}$ bortezomib for $48 \mathrm{~h}$. $\alpha$-Tubulin served as loading control. (h) Cell death in response to $100 \mathrm{nM}$ bortezomib was determined by propidium iodide staining. Depletion of procaspase-8 significantly reduced cell death. siRNA transfection preceded drug addition by $24 \mathrm{~h}$ to provide efficient target depletion $24 \mathrm{~h}$ subsequent to bortezomib addition (see Supplementary Figure 8). Data are shown as mean \pm S.D., asterisks indicate significant differences $(P<0.05$, Student's $t$-test). (i) Depletion of FADD by siRNA transfection. As in (d), HeLa-Bcl-2 cells were analysed for FADD expression at the indicated times following siRNA transfection. (j) As in (e), HeLa Bcl-2 cells depleted of FADD expression with $100 \mathrm{nM}$ FADD siRNA were analysed for DEVD FRET probe cleavage by flow cytometry following treatment with $100 \mathrm{nM}$ bortezomib. siRNA transfection preceded drug addition by $24 \mathrm{~h}$ to provide efficient target depletion $24 \mathrm{~h}$ subsequent to bortezomib addition (see Supplementary Figure 8). Bars display changes in FRET substrate cleavage (\%) above untreated controls. Data represent mean \pm S.D. from $n=9$ values obtained from bootstrap resampling of independent triplicates. Depletion of FADD significantly reduced FRET probe cleavage $(P<0.05$, U-test). Experiment was repeated with similar results 
timed so that protein were maximally depleted before residual caspase processing set in (see Materials and Methods and Supplementary Figure 8).

As caspase-3 is the most potent DEVDase, we first depleted HeLa-Bcl-2 cells of procaspase-3 (Figure 4a, Supplementary Figure 8A). Interestingly, DEVDase activity arising from bortezomib exposure was not reduced (Figure 4b), and time-lapse imaging indicated that the frequency of DEVDase activation was not notably affected (see Figure 5f). In control experiments, the depletion of procaspase-3 however was sufficient to impair TRAIL/ cycloheximide (CHX)-induced apoptosis in HeLa cells (Supplementary Figure 4). We next also employed caspase- 3-deficient MCF-7 cells overexpressing Bcl-2. Consistent with results shown for $\mathrm{HeLa}$ and $\mathrm{H} 460$ cells, MCF-7-Bcl-2 but not parental MCF-7 cells were refractory to STS-induced apoptosis and DEVD probe cleavage (Supplementary Figure 5). Depleting MCF-7-Bcl-2 cells of procaspase-7 eliminated all DEVD-preferring caspases (Figure 4c, Supplementary Figure 8B). Interestingly, independent of caspase-7, proteasome inhibition resulted in cells localising across a continuous spectrum from intact to cleaved FRET substrate (Figure $4 d$ ). These data therefore indicate that FRET probe cleavage apparently does not depend on a significant activation of the major DEVDases caspase-3 or -7 . a

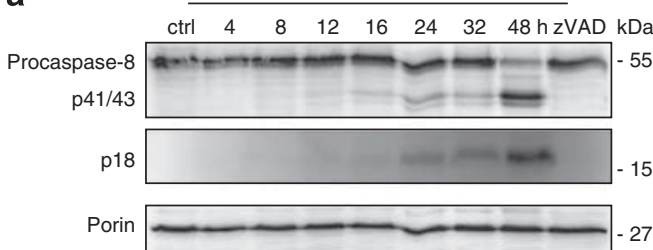

b
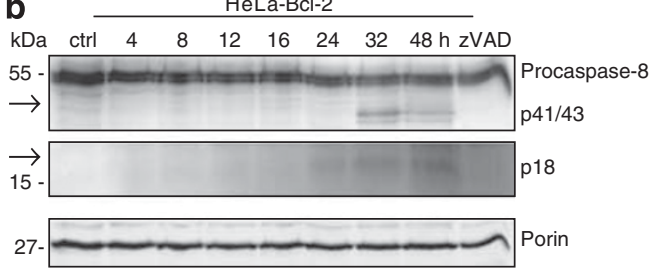

HeLa-Bcl-2

C

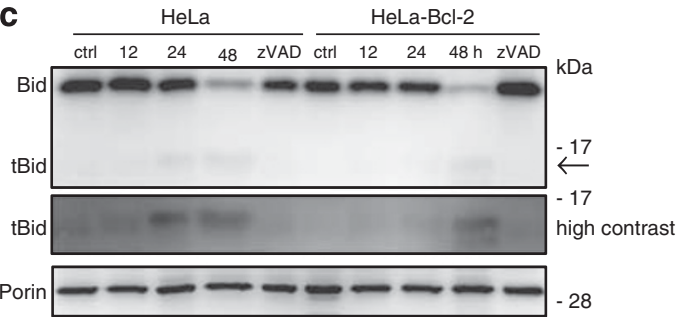

d
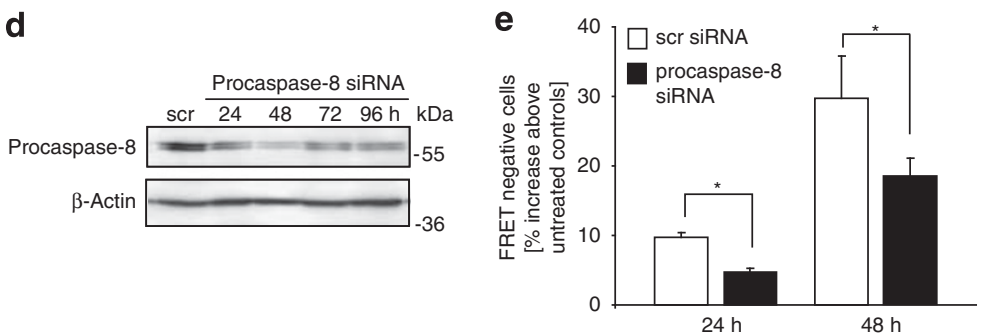

$\mathbf{g}$

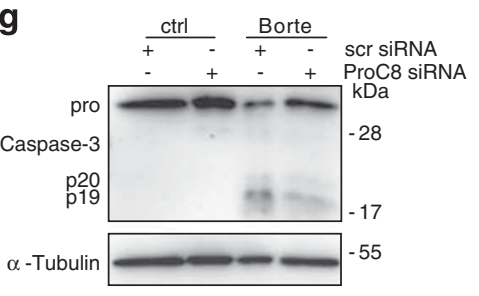

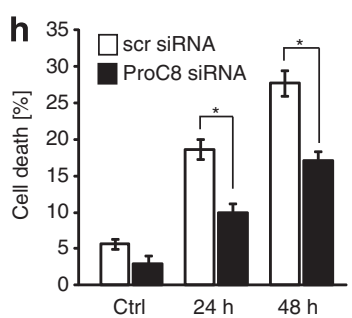

i

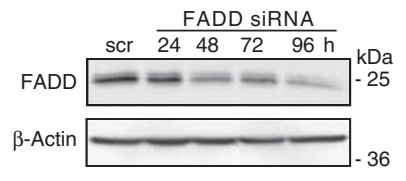

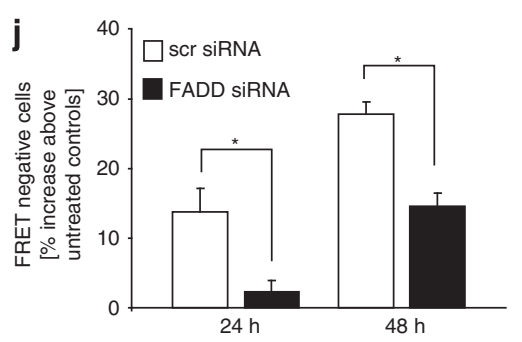


MOMP-independent DEVDase activity arises from FADDdependent caspase-8 activation. As caspase- 8 is known to possess substantial DEVDase activity, ${ }^{18}$ we next tested its involvement in generating the caspase activity we observed. Procaspase- 8 was processed in response to bortezomib in HeLa cells (Figure 5a) at times correlating with caspase-3 activation (Figure 1b), as would be expected from caspase-3dependent feedback processing. In HeLa-Bcl-2 cells, only low amounts of cleaved caspase-8 were detected (Figure $5 \mathrm{~b}$ ). The cleavage of Bid, a physiological caspase-8 and -3 substrate, correlated with procaspase- 8 processing in both scenarios (Figure $5 \mathrm{c}$ ). When suppressing procaspase-8 expression by siRNA transfection (Figure $5 d$, Supplementary Figure $8 C$ ), DEVDase activity in response to proteasome inhibition was significantly reduced (Figure $5 \mathrm{e}$ ). Likewise, time-lapse imaging indicated that procaspase- 8 but not procaspase-3 depletion massively reduced the percentage of cells displaying DEVDase activity (Figure 5f). Furthermore, procaspase-3 processing into p20/p19 subunits and cell death were reduced upon procaspase-8 silencing (Figure $5 \mathrm{~g}$ and $h$ ). These data therefore indicate that in response to proteasome inhibition, caspase- 8 serves as the apical caspase in MOMP-impaired cells.

Caspase- 8 activation requires the dimerisation and autocatalytic processing of procaspase- $8,{ }^{20}$ and Fas-associated death domain (FADD) is the essential recruitment protein for procaspase-8 dimerisation. Depleting FADD in HeLa-Bcl-2 cells (Figure 5i, Supplementary Figure $8 \mathrm{D}$ ) resulted in significantly reduced DEVDase activity in response to proteasome inhibition (Figure $5 \mathrm{j}$ ). In control experiments, depletion of caspase-8 and FADD was sufficient to impair death receptor-mediated apoptosis in HeLa cells (Supplementary Figure 4), showing that the siRNAs used also conferred protection in a canonical apoptosis signalling model. Our results therefore indicate that the MOMPindependent, mild DEVDase activity detected in response to proteasome inhibition arises from FADD-dependent caspase-8 activation.

\begin{abstract}
Apical caspase-8 activation is independent of death receptor ligands. We next investigated whether canonical death receptor pathways are required to establish apical caspase- 8 activity. Proteasome inhibition may induce the secretion of death receptor ligands such as TRAIL, tumour necrosis factor- $\alpha$ (TNF- $\alpha$ ) or fas ligand (FasL), which may in turn activate caspase-8 by autocrine death receptor activation. Pretreatment of parental HeLa cells with death receptor-neutralising antibodies fully blocked caspase-3 processing following TRAIL, TNF- $\alpha$ or FasL exposure (Figure 6a). Pretreatment of HeLa-Bcl-2 cells with the receptor-neutralising antibodies alone or in combination, however, did not affect bortezomib-induced residual procaspase- 3 processing (Figure $6 \mathrm{~b}$ and $\mathrm{c}$ ). These data therefore indicate independence of autocrine death ligand signalling.
\end{abstract}

Proteasome inhibition induces autophagy, which contributes to caspase-8 processing and cell death. Autophagy can increase as a compensatory means of protein degradation when the proteasomal pathway is blocked. ${ }^{21}$ Furthermore, in proliferating T cells caspase-8, in complex with FADD and receptor-interacting serine/ threonine-protein kinase 1 (RIPK1), was found activated on autophagosomal membranes. ${ }^{22}$ We therefore investigated whether a link between autophagic signalling, caspase-8 processing and cell death could be observed in response to proteasome inhibition.

Autophagic flux increased in HeLa Bcl-2 cells following bortezomib exposure, as evidenced by the accumulation of autophagy marker protein LC3 and the accumulation of lipidated LC3-II when inhibiting lysosomal proteases using E64 D and pepstatin A (Figure 7a). Accordingly, the amounts of p62, an autophagy adaptor protein and indicator of protein aggregation that accumulates upon proteasome inhibition, increased following bortezomib treatment (Figure 7a and b), and a further increase, indicative of elevated autophagic flux, was found upon E64 D/pepstatin A addition (Figure 7a). The levels of FADD also accumulated strongly, whereas increases in RIPK1 were modest and transient (Figure 7b). RIPK1 is a physiological substrate of caspase-8, and its late loss was prevented by zVAD-fmk (not shown). Autophagy induction was also detected when expressing a mCherry-GFP-LC3 fusion protein. The number of GFP-positive punctae, representing autophagosomes, increased strongly in response to bortezomib (Figure 7c). The GFP fluorescence is quenched upon fusion of autophagosomes with lysosomes, whereas mCherry fluorescence persists. ${ }^{23}$ The number and intensities of mCherry punctae were higher than the GFP signals (Figure 7c), indicating an increase in autolysosomes and overall autophagic flux.

Autophagy induction was linked to caspase-8 activation, as 3-methyl adenine (3-MA), an inhibitor of autophagosome formation, but not necrostatin, an inhibitor of RIPK1, reduced procaspase-8 processing (Figure 7d). LC3-I to LC3-II conversion was noticeably impaired, confirming autophagy inhibition in 3-MA/bortezomib co-treatments (Figure 7d). When investigating whether autophagy inhibition by 3-MA also reduced the overall amount of cell death following bortezomib addition, we observed a mild but nevertheless significant protection (Figure 7e). RIPK1 inhibition did not reduce cell death (Figure 7e), suggesting that necroptosis or excessive autophagy arising from RIPK1 activities ${ }^{24-25}$ did not contribute to cell death. The reduction in cell death might appear rather modest; however, as 3-MA potently induced apoptosis in HeLa cells (Supplementary Figure 6A), and as cell death of HeLa Bcl-2 cells upon bortezomib/3-MA co-treatments was z-VAD-fmk sensitive (Supplementary Figure $6 \mathrm{~B}$ ), it is likely that an alternative form of caspasedependent death, which we do not further characterise here, is synergistically promoted at these conditions.

Given the above results, we next also blocked autophagy more specifically by depleting Atg5. Atg5 is essential for autophagosome formation, is found conjugated to Atg12 and it was shown that caspase-8 activation during T-cell proliferation requires the FADD-dependent docking to Atg5-Atg12 on autophagosomes. $^{22}$ Indeed, depleting HeLa-Bcl-2 cells of Atg5 expression blocked caspase-8 processing in response to bortezomib (Figure 7f) and significantly reduced cell death (Figure $7 \mathrm{~g}$ ). Our data therefore show that caspase-8 processing is strongly impaired when inhibiting autophagy 
a
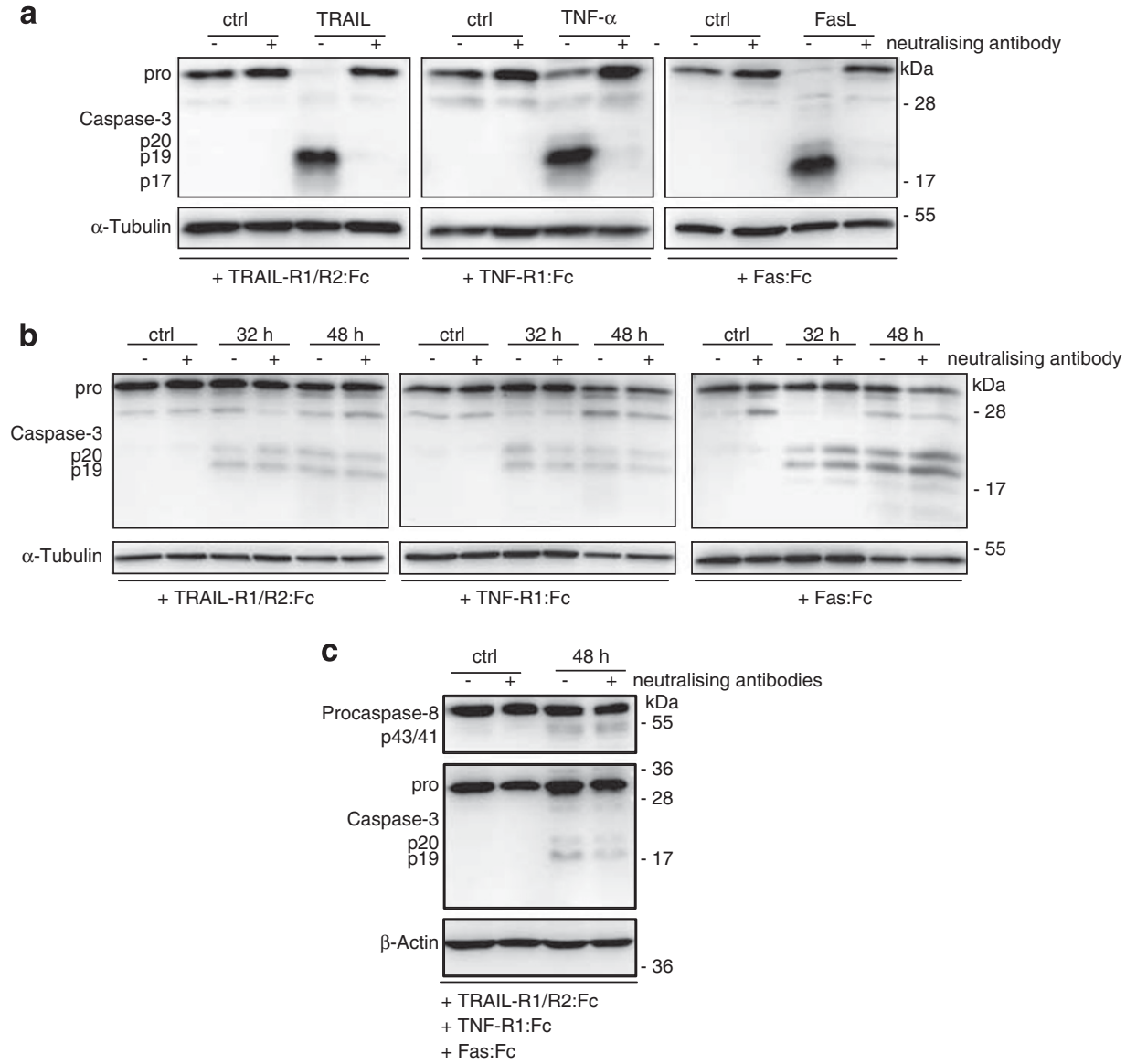

Figure 6 Apical caspase-8 activation in response to proteasome inhibition is independent of death receptor ligands. (a) Neutralisation of the extrinsic pathway in parental HeLa cells. At $2 \mathrm{~h}$ pretreatment with $5 \mu \mathrm{g} / \mathrm{ml}$ tumour necrosis factor-related apoptosis-inducing ligand-receptor 1 (TRAlL-R1):Fc $+5 \mu \mathrm{g} / \mathrm{ml}$ TRAIL-R2:Fc, $5 \mu \mathrm{g} / \mathrm{ml}$ tumour necrosis factor-receptor 1 (TNF-R1):Fc or $10 \mu \mathrm{g} / \mathrm{ml}$ Fas:Fc antibodies, respectively, completely abolished extrinsically induced caspase-3 processing. Cells were treated for $6 \mathrm{~h}$ with $10 \mathrm{ng} / \mathrm{ml}$ TRAIL plus $1 \mu \mathrm{g} / \mathrm{ml}$ cycloheximide (CHX) or $100 \mathrm{ng} / \mathrm{ml}$ Fas ligand (FasL) plus $1 \mu \mathrm{g} / \mathrm{ml} \mathrm{CHX}$ or for $8 \mathrm{~h}$ with $100 \mathrm{ng} / \mathrm{ml}$ TNF- $\alpha$ plus $1 \mu \mathrm{g} / \mathrm{ml} \mathrm{CHX.} \alpha-T u b u l i n$ served as loading control. (b) Inhibition of death receptors did not diminish submaximal procaspase-3 processing in response to proteasome inhibition in HeLa-Bcl-2 cells. Cells were pretreated as in (a), and subsequently exposed to $100 \mathrm{nM}$ bortezomib ([(1R)-3-methyl-1-(\{(2S)-3-phenyl-2-[(pyrazin-2-ylcarbonyl)amino]propanoyl\}amino)butyl]boronic acid) for 32 or $48 \mathrm{~h}$. $\alpha$-Tubulin served as loading control. (c) Procaspase- 8 and -3 processing was investigated when using a combination of all neutralising antibodies. $\beta$-Actin served as loading control

pharmacologically or by Atg5 depletion, indicating that autophagosome formation is an important contributor to caspase-8 activation following proteasome inhibition.

XIAP depletion and Smac-derived peptides enhance proteasome inhibitor-induced apoptosis in Bcl-2overexpressing cells. Most cells require the mitochondrial pathway to execute apoptosis. In MOMP-impaired cells, XIAP prevents caspase-8-mediated caspase-3 activation in response to death ligands. ${ }^{26}$ We therefore hypothesised that DEVDase activity evoked by proteasome inhibition could be enhanced by XIAP depletion or by XIAP-antagonising Smac peptides. XIAP depletion (Figure 8a, Supplementary Figure $8 \mathrm{E})$ indeed significantly enhanced DEVD probe cleavage and increased cell death (Figure $8 \mathrm{~b}$ and $\mathrm{c}$ ). To circumvent the requirement for transfection procedures, we also synthesised a XIAP-antagonising peptide (AVPIA) fused to an HIVderived import sequence. ${ }^{27}$ Control measurements in HeLa-Bcl-2 and $\mathrm{H} 460-\mathrm{Bcl}-2$ cells indicated that the peptide alone did not evoke noticeable cell death (Figure 8d and e), nor did it enhance STS-induced death (Supplementary Figure 7). AVPIA peptide/bortezomib co-treatments, however, markedly enhanced apoptosis in HeLa-Bcl-2 and $\mathrm{H} 460-\mathrm{Bcl}-2$ cells (Figure $8 \mathrm{~d}$ and $\mathrm{e}$ ), indicating that antagonising XIAP is a promising approach to overcome the apoptosis resistance of MOMP-impaired human cancer cells.

\section{Discussion}

We identified that proteasome inhibition promotes the FADDdependent activation of caspase-8 in human cancer cells in which the mitochondrial apoptosis pathway is blocked, and that autophagy induction contributes to caspase-8 activation. Caspase-8 activity is low and persistent, without leading to immediate apoptosis. Cellular commitment to apoptosis can be promoted by antagonising XIAP. This provides a strategy to restore the susceptibility of highly resistant human cancer cells that cannot execute apoptosis via the mitochondrial pathway. 
a

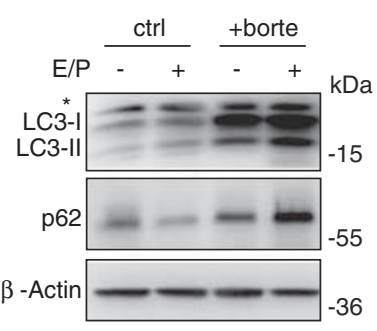

b

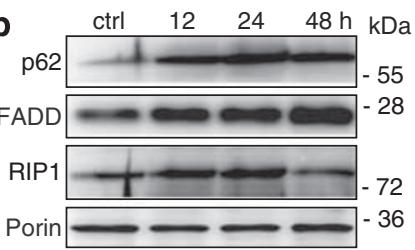

c

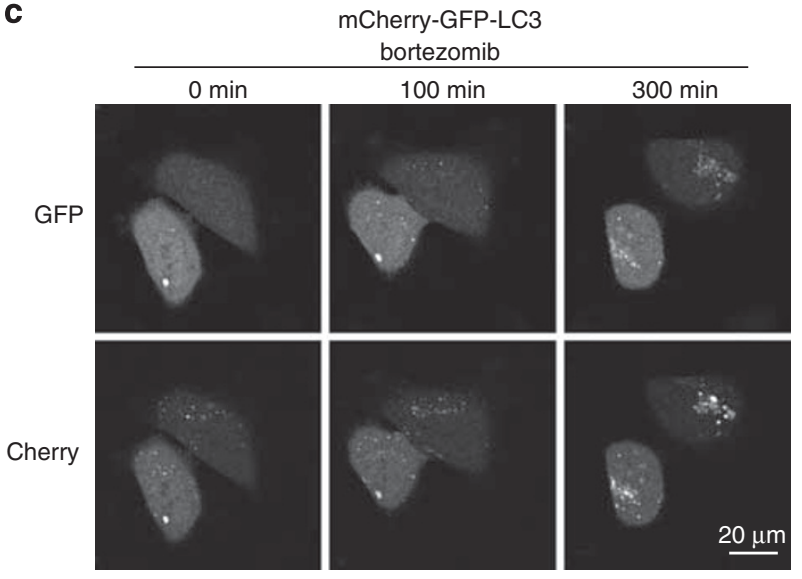

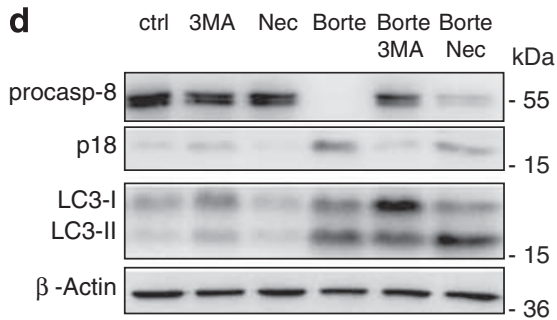

f

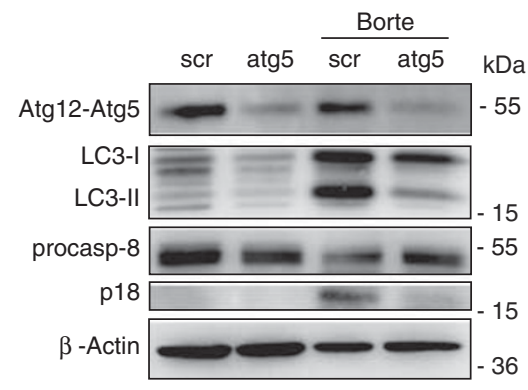

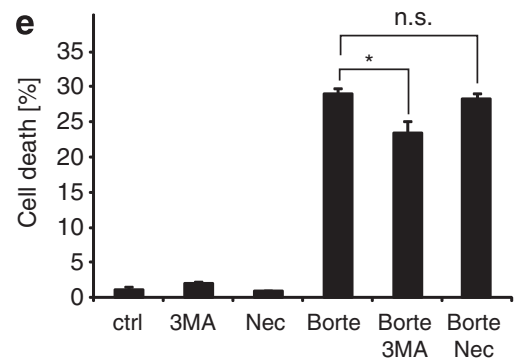

g

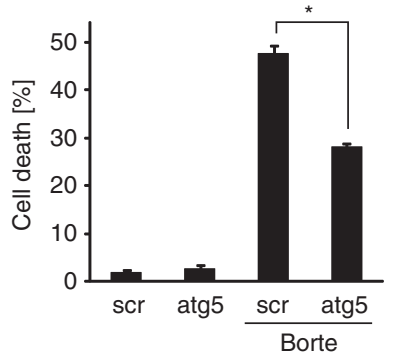

Figure 7 Autophagy strongly contributes to caspase-8 processing in response to proteasome inhibition. (a) Whole-cell extracts of HeLa Bcl-2 cells treated with $100 \mathrm{nM}$ bortezomib ([(1R)-3-methyl-1-(\{(2S)-3-phenyl-2-[(pyrazin-2-ylcarbonyl)amino]propanoyl\}amino)butyl]boronic acid) for $32 \mathrm{~h}$ in the presence or absence of inhibitors of lysosomal proteases were probed for LC3 and p62. Asterisk indicates an unspecific band. $\beta$-Actin served as loading control. (b) Whole-cell extracts of HeLa Bcl-2 cells treated with $100 \mathrm{nM}$ bortezomib for the indicated times were probed for the accumulation of p62, Fas-associated death domain (FADD) or receptor-interacting protein kinase 1 (RIPK1). Porin served as loading control. (c) HeLa Bcl-2 cells expressing an mCherry-green fluorescent protein (GFP)-LC3 fusion protein were analysed for the induction of autophagy subsequent to addition of $100 \mathrm{nM}$ bortezomib by confocal microscopy. GFP punctae represent autophagosomes, mCherry punctae represent both autophagosomes and autolysosomes. (d) Procaspase-8 processing and LC3 accumulation and conversion was analysed in HeLa Bcl-2 cells treated with $5 \mathrm{mM}$ 3-methyl adenine (3-MA), $10 \mu \mathrm{M}$ necrostatin, $50 \mathrm{nM}$ botezomib or combinations thereof for $32 \mathrm{~h}$. 3-MA significantly reduced bortezomib-induced procaspase-8 processing and LC3-I to LC3-II conversion. $\beta$-Actin served as loading control. (e) Cell death of HeLa Bcl-2 cells in response to treatments as in (d) was determined by propidium iodide staining. Data are shown as means \pm standard deviation (S.D.) from $n=3$ parallel independent cultures. Asterisk indicates significant difference $(P<0.05$, Student's $t$-test). Experiment was repeated with similar results. (f) Atg5 depletion blocks procaspase-8 processing. Atg5 was depleted in HeLa Bcl-2 cells using short hairpin RNA (shRNA) transfection. At $48 \mathrm{~h}$ subsequent to transfection, cells were exposed to $50 \mathrm{nM}$ bortezomib for $40 \mathrm{~h}$. Whole-cell lysates were analysed for the amount of Atg12-Atg5 conjugates, LC3-I accumulation and conversion to LC3-II, and procaspase-8 processing. $\beta$-Actin served as loading control. (g) Cell death of HeLa Bcl-2 cells in response to treatments as in (f) was determined by propidium iodide staining. Data are shown as mean \pm S.D. from $n=3$ parallel independent cultures. Asterisk indicates significant difference $(P<0.05$, Student's $t$-test). All experiments were repeated at least once and similar results were obtained

Proteasome inhibition affects the relative abundance of hundreds of cellular proteins and is believed to induce apoptosis mainly through the mitochondrial pathway by the accumulation of $\mathrm{BH} 3-$ only proteins. We showed that in cells in which the mitochondrial apoptosis pathway is blocked, caspase-8 can be activated in response to proteasome inhibition, and that this was the predominant response in the majority of cells investigated. Although previous studies already suggested a role for caspase-8 in apoptosis following proteasome inhibition, ${ }^{28-29}$ time-lapse and single-cell analyses here unequivocally showed that caspase- 8 acts as the apical caspase in this treatment paradigm rather than being 


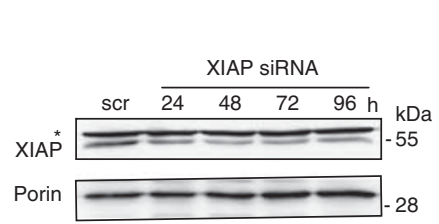

b

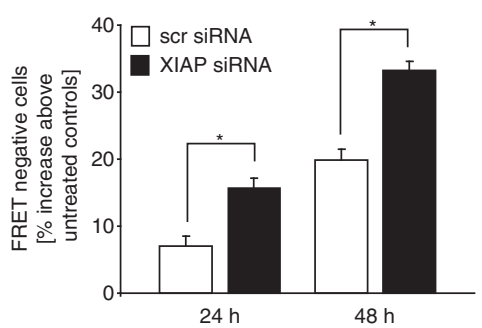

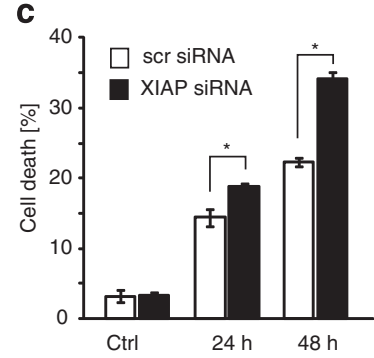

d

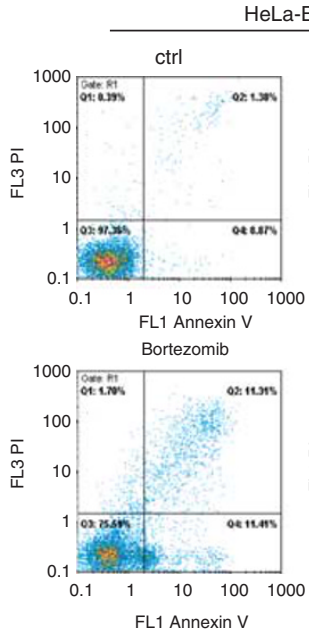

HeLa-Bcl-2
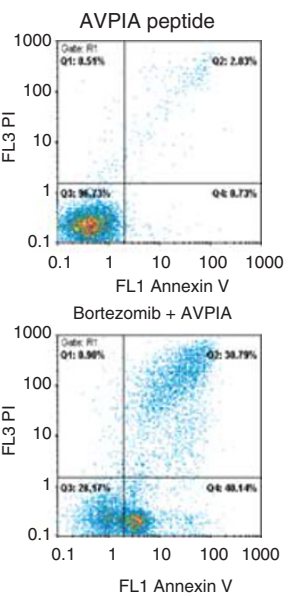

e

$\mathrm{H} 460-\mathrm{Bcl}-2$
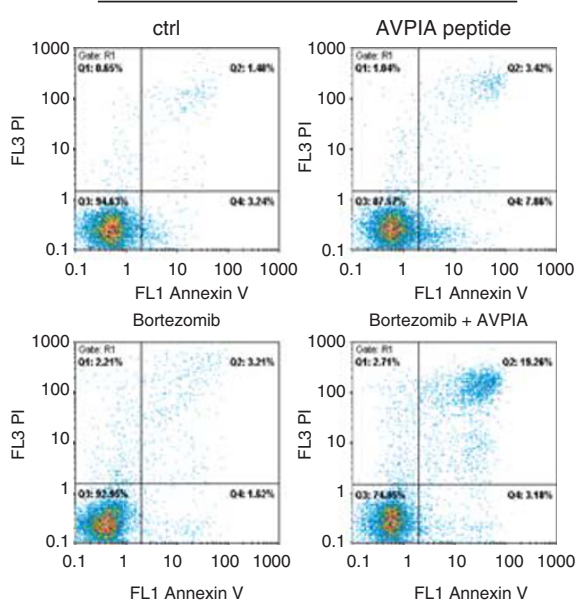

Figure 8 X-linked inhibitor of apoptosis (XIAP) depletion and Smac-derived XIAP-antagonising peptides enhance proteasome inhibitor-induced DEVDase activation and apoptosis in Bcl-2-overexpressing cells. (a) Depletion of XIAP by small interfering RNA (siRNA) transfection. HeLa-Bcl-2 cells were analysed for XIAP expression at the indicated times following siRNA transfection. Asterisk indicates an unspecific band. $\beta$-Actin served as loading control. A scrambled siRNA (scr) was transfected in control cells. (b) HeLa Bcl-2 cells depleted of XIAP expression were analysed for DEVD Förster resonance energy transfer (FRET) probe cleavage by flow cytometry following treatment with $100 \mathrm{nM}$ bortezomib ([(1R)-3-methyl-1-(\{(2S)-3-phenyl-2-[(pyrazin-2-ylcarbonyl)amino]propanoyl\}amino)butyl]boronic acid). siRNA transfection preceded drug addition by $24 \mathrm{~h}$ to provide efficient target depletion $24 \mathrm{~h}$ subsequent to bortezomib addition (see Supplementary Figure 8). Depletion of XIAP significantly enhanced FRET probe cleavage. Data represent mean \pm (S.D.) from $n=9$ values obtained from bootstrap resampling of independent treatment and control triplicates. Experiment was repeated with similar results. (c) Cell death in response to $100 \mathrm{nM}$ bortezomib was determined by propidium iodide staining. Depletion of XIAP significantly enhanced cell death following treatment of HeLa Bcl-2 cells with $100 \mathrm{nM}$ bortezomib. Data are shown as means \pm standard deviation (S.D.), asterisks indicate significant differences $(P<0.05$, Student's $t$-test). (d) Smac-derived XIAP-antagonising AVPIA peptides enhance apoptosis execution in response to proteasome inhibition in HeLa Bcl-2 cells. Apoptotic cell death was measured by flow cytometry using AnnexinV-fluorescein isothiocyanate (FITC) and propidium iodide staining. Mild responses were detected following proteasome inhibition by bortezomib $(100 \mathrm{nM}, 32 \mathrm{~h})$. Addition of AVPIA peptide $(100 \mu \mathrm{M})$ significantly enhanced cell death. Untreated cells or cells receiving only AVPIA peptide did not undergo apoptosis execution. Experiment was repeated with similar results. (e) As in (d), H460 cells overexpressing Bcl-2 were exposed to bortezomib, AVPIA peptide or both. Co-treatment strongly enhanced cell death following $32 \mathrm{~h}$ of treatment. Experiment was repeated with similar results

processed subsequent to caspase-3, which has largely overlapping substrate specificities. ${ }^{18}$

Canonical activation of caspase- 8 requires the dimerisation and autocatalytic processing at multiprotein platforms, such as the DISC during extrinsic apoptosis. ${ }^{20,30}$ We here showed that autophagy induction contributes significantly to FADDdependent caspase-8 activation. A link between autophagy, FADD and caspase-8 activation was indeed reported previously during T-cell expansion and cell cycle progression, ${ }^{22,31}$ indicating that basal autophagy in proliferating $\mathrm{T}$ cells may establish low caspase- 8 activities. Of note, autophagy and caspase- 8 activity in these scenarios are physiologically required for cell proliferation rather than inducing death. ${ }^{22,25,31}$ Protein degradation might quickly remove or restrict naturally occurring, sublethal caspase-8 activities in these cells. Proteasome inhibition instead, apart from enhancing caspase-8 activation through inducing autophagy, additionally may cause an abnormal accumulation of active caspase- 8 through blocking protein degradation. This would likely contribute to rendering autophagy-dependent caspase-8 activation to become potentially lethal.

Mechanistically, it was shown that caspase-8 and FADD can bind to Atg5/Atg12 clusters on autophagosomal membranes, ${ }^{22}$ which could promote caspase-8 activation through induced proximity. The necroptosis inducer and caspase-8 substrate RIPK1 is part of these complexes; however, we could not find that RIPK1 activity contributed to death. This is consistent with the notion that RIPK1 only induces autophagydependent necroptosis when caspase- 8 is absent. ${ }^{22}$ The late and zVAD-fmk-sensitive loss in RIPK1 observed in our experiments indeed rather suggests that caspase- 8 activation upon proteasome inhibition may actively suppress necroptotic responses.

We cannot rule out that apart from autophagosomes, additional scaffolds for caspase-8 activation are formed upon proteasome inhibition. Although we excluded that extrinsic 
stimulation of death receptors contributed to caspase-8 activation, it was shown that impaired protein degradation can induce an abnormal accumulation of high-turnover death receptors. $^{32}$ This may result in artificial death receptor oligomerisation and caspase- 8 activation also in the absence of death ligands. Caro-Maldonado et al. ${ }^{33}$ showed that MOMP-impaired cells can activate caspase- 8 independent of death receptors following glucose deprivation by an as of yet unresolved mechanism. As proteasomal protein degradation is highly energy-dependent, lack of sufficient ATP as a consequence of glucose deprivation might promote autophagy and caspase- 8 activation in a manner related to our observations.

As most proapoptotic chemotherapeutics induce death via the mitochondrial pathway, elevated expression of antiapoptotic $\mathrm{Bcl}-2$ family members poses a significant challenge to the development of efficient anticancer therapies. This is of clinical relevance as the expression of $\mathrm{Bcl}-2, \mathrm{Bcl}-\mathrm{xL}$ or $\mathrm{Mcl}-1$ has been associated with poor prognosis or increased risk of recurrence in various cancers, including chronic lymphocytic leukaemia, follicular lymphoma and breast cancer. ${ }^{34-36}$ Although Bcl-2-inhibiting compounds are currently in preclinical and clinical trials, no single compound is sufficient to antagonise all antiapoptotic family members with high efficiency or without significant off-target effects. ${ }^{37}$ The direct activation of executioner caspases by caspase-8 offers the possibility to bypass the requirement for MOMP, but in most cells is significantly impaired by the presence of XIAP, a major regulator of the caspase-8/-3 axis. ${ }^{26,38}$ We showed that the death ligand-independent apical caspase-8 activation upon proteasome inhibition can be exploited to execute apoptosis in otherwise highly resistant $\mathrm{Bcl}-2$-overexpressing cells when XIAP is antagonised. This may provide a new and attractive strategy to induce death in cancer cells that otherwise do not respond to proapoptotic chemotherapeutics.

\section{Materials and Methods \\ Reagents. Bortezomib was from Millennium Pharmaceuticals (Cambridge, MA, USA), Epoxomicin from Sigma-Aldrich (Dublin, Ireland) and MG-132 from Biomol (Plymouth Meeting, PA, USA). STS, CHX, tunicamycin and etoposide were purchased from Alexis (San Diego, CA, USA). zVAD-fmk was from Bachem (St. Helen's, UK). Human recombinant TRAIL was from Leinco Technologies (St. Louis, MO, USA), human anti-Fas antibody was from (MBL, Caltag-Medystems, Buckingham, UK), TNF- $\alpha$ was from PeproTech EC Ltd (London, UK). Necrostatin-1, pepstatin A, E64 D and 3-MA were purchased from Calbiochem/Merck (Nottingham, UK). \\ Peptide synthesis. A peptide comprised of an $\mathrm{NH}_{2}$-terminal Smac-derived IAP-antagonising sequence (AVPIAQK) and a $\mathrm{COOH}$-terminal HIV-TAT protein- transduction domain (GRKKRRQRRRPPQ) ${ }^{27}$ was prepared by standard solid- phase peptide synthesis.}

Cell culture. Cells were cultivated in RPMI-1640 medium (Sigma-Aldrich) supplemented with $2 \mathrm{mM} \mathrm{L-glutamine,} 10 \%$ (v/v) heat-inactivated foetal bovine serum, $100 \mathrm{U} / \mathrm{ml}$ penicillin and $100 \mu \mathrm{g} / \mathrm{ml}$ streptomycin (Sigma-Aldrich) in a humidified atmosphere with $5 \% \mathrm{CO}_{2}$ at $37^{\circ} \mathrm{C}$.

DNA and siRNA transfection. HeLa cells were transfected with pCFPDEVD-YFP, pIMS-RP or pmCherry-GFP-LC3 plasmid DNA using Lipofectamine 2000 (Invitrogen, Paisley, UK) according to the manufacturer's instructions. siRNA sequences known to specifically silence the expression of procaspase-3, procaspase-7, procaspase-8, FADD, XIAP or Atg5 are listed in Supplementary Material 1. siRNAs were transfected at a final concentration of 100-150 nM together with $800 \mathrm{ng}$ pCFP-DEVD-YFP in six-well plates. The relative timing of siRNA transfections before drug addition ( $24 \mathrm{~h}$ for procaspase-3, -8, FADD, XIAP; $48 \mathrm{~h}$ for procaspase-7, Atg5) was optimised to achieve maximal protein depletion at a time of $24 \mathrm{~h}$ post-bortezomib addition. The efficiency and maintenance of protein depletion in the presence of bortezomib is shown in Supplementary Figure 8. Turbofect (Fermentas UK, York, UK) was used following the manufacturer's guidelines to transfect $\mathrm{H} 460$ or MCF-7 cells.

Immunoblotting. Cells were harvested and spun at $200 \times g$ for $3 \mathrm{~min}$. Cell pellets were resuspended in SDS lysis buffer $(62.5 \mathrm{mM}$ Tris- $\mathrm{HCl}, \mathrm{pH} 6.8,10 \%(\mathrm{v} / \mathrm{v})$ glycerin, $2 \%(\mathrm{w} / \mathrm{v})$ SDS, $1 \mathrm{mM}$ phenylmethylsulfonyl fluoride, $1 \mu \mathrm{g} / \mathrm{ml}$ pepstatin $\mathrm{A}$, $1 \mu \mathrm{g} / \mathrm{ml}$ leupeptin and $5 \mu \mathrm{g} / \mathrm{ml}$ aprotinin) and incubated at $95^{\circ} \mathrm{C}$ for $20 \mathrm{~min}$. Protein content was determined with the Micro BCA Protein Assay Kit (Thermo Scientific, Dublin, Ireland). Equal amounts of protein $(20 \mu \mathrm{g})$ were run on SDS-polyacrylamide gels and subjected to immunoblotting as described before. ${ }^{17}$ Precision Plus Protein Standards (Bio-Rad, Munich, Germany) or PageRuler Prestained Protein Ladder Plus (Fermentas UK) molecular weight markers were used. A detailed list of antibodies used is provided in Supplementary Material 1. Immunoblots were developed using the Immobilon Western Chemiluminescent HRP Substrate (Millipore, Molsheim, France). Chemiluminescence was detected at 12-bit dynamic range using a Fuji LAS 4000 CCD system (Fujifim UK Ltd, Bedfordshire, UK).

Inhibition of the death receptor pathway. Human neutralising antibodies against TRAIL-R1 and -R2 (ALX-522-004-C050 and ALX-522-005C050), TNF-R1 (ALX-522-013-C050) and Fas (ALX-522-002-C050) were purchased from Enzo Life Sciences Ltd (Exeter, UK). Antibodies were added at a final concentration of $5-10 \mu \mathrm{g} / \mathrm{ml} 2 \mathrm{~h}$ before drug additions.

Flow cytometry. FRET flow cytometry was carried out using a Partec Cyflow ML16 flow cytometer (Partec, Münster, Germany) or a BD LSRIl flow cytometer (Oxford, UK). Cells were re-suspended in ice-cold phosphate-buffered saline and 10000 gated events were acquired for each sample. Detailed settings for FRET flow cytometry and AnnexinV-FITC/propidium iodide (PI) cytometry as provided in Supplementary Material 1. For Annexin-V/PI staining cells were trypsinised and incubated in binding buffer ( $10 \mathrm{mM}$ HEPES, $140 \mathrm{mM} \mathrm{NaCl}, 2.5 \mathrm{mM} \mathrm{CaCl}$ ) containing Annexin-V-FITC (5 $\mathrm{l} / \mathrm{ml})$ (BioVision, Mountain View, CA, USA) and PI ( $2 \mu \mathrm{g} / \mathrm{ml}$, Sigma-Aldrich) for $20 \mathrm{~min}$ at room temperature in the dark. Basic data acquisition in .fcs file format and analysis were performed using the Partec Flow Max (Partec) or Cyflogic (CyFlo Ltd, Turku, Finland) software. Ratiometric analysis of cellular fluorescence signals was performed using MATLAB (The Mathworks, Cambridge, UK) scripts developed in-house.

Fluorescence microscopy and digital imaging. Cells were cultivated on $22 \mathrm{~mm}$ glass bottom dishes (Willco BV, Amsterdam, the Netherlands). FRET probe fluorescence was observed using a Nikon Eclipse TE2000-S microscope equipped with a $40 \times$ numerical aperture 1.3 oil-immersion objective and a dual camera adaptor (Nikon, MicronOptical, Enniscorthy, Ireland). Cells were subjected to time lapse FRET imaging as described before. ${ }^{39}$ For the release of the MOMP reporter IMS-RP from the mitochondria into the cytosol, we analyzed the cellular fluorescence standard deviation from the average pixel intensity of individual cells. ${ }^{40}$ Compartmentalised IMS-RP contributes to a high S.D. The S.D. drops upon release of IMS-RP towards a homogeneous distribution throughout the cell. Baselines before the release were scaled to $100 \%$. mCherry-GFP-LC3 fluorescence was observed using a Zeiss LSM710 confocal microscope. A detailed description of the imaging procedures is provided in Supplementary Material 1.

Statistics. Data are given as means \pm S.D. or S.E.M. For statistical comparison, Student's $t$-test or ANOVA followed by Tukey's test were used for normally distributed data. Otherwise, Mann-Whitney U-test was used. $P$-values smaller than 0.05 were considered to be statistically significant.

\section{Conflict of interest}

The authors declare no conflict of interest.

Acknowledgements. This work was supported by grants from the Research Committee of the Royal College of Surgeons in Ireland, the Health Research Board 
Ireland (RP/2006/258; RP/2008/7) and Science Foundation Ireland (09/RFP/ BIC2375) awarded to MR, the National Biophotonics and Imaging Platform Ireland (Higher Education Authority PRTLI Cycle 4) and the European Union (FP7 Health APO-SYS). We are grateful to Dr. Douglas Green (St. Jude Children's Research Hospital, Memphis), Dr. Frank Kruyt (University Medical Center Groningen), Drs. John Albeck and Peter Sorger (Harvard Medical School, Boston), Dr. Scott Oakes (University of California, San Francisco), Dr. Nathan Brady (German Cancer Research Center, Heidelberg), and Dr. Elaine Kay and Peter Jakob (Royal College of Surgeons in Ireland and Beaumont Hospital, Dublin) for the supply of cell lines, plasmids and additional materials. We also thank Eimear Costelloe, Kami Jastrzebski and Dr. Tytus Bernas for technical assistance and helpful advice.

1. Carlucci A, Lignitto L, Feliciello $A$. Control of mitochondria dynamics and oxidative metabolism by cAMP, AKAPs and the proteasome. Trends Cell Biol 2008; 18: 604-613.

2. Jung T, Catalgol B, Grune T. The proteasomal system. Mol Aspects Med 2009; 30: 191-296.

3. Brenner D, Mak TW. Mitochondrial cell death effectors. Curr Opin Cell Biol 2009; 21: 871-877.

4. Bhalla S, Balasubramanian S, David K, Sirisawad M, Buggy J, Mauro L et al. PCl-24781 induces caspase and reactive oxygen species-dependent apoptosis through NF-kappaB mechanisms and is synergistic with bortezomib in lymphoma cells. Clin Cancer Res 2009; 15: 3354-3365

5. Colado E, Alvarez-Fernandez S, Maiso P, Martin-Sanchez J, Vidriales MB, Garayoa M et al. The effect of the proteasome inhibitor bortezomib on acute myeloid leukemia cells and drug resistance associated with the CD34+ immature phenotype. Haematologica 2008; 93: 57-66.

6. Li C, Li R, Grandis JR, Johnson DE. Bortezomib induces apoptosis via Bim and Bik up-regulation and synergizes with cisplatin in the killing of head and neck squamous cell carcinoma cells. Mol Cancer Ther 2008; 7: 1647-1655.

7. Tan TT, Degenhardt K, Nelson DA, Beaudoin B, Nieves-Neira W, Bouillet $P$ et al. Key roles of BIM-driven apoptosis in epithelial tumors and rational chemotherapy. Cancer Cell 2005 7: 227-238.

8. Nikrad M, Johnson T, Puthalalath $\mathrm{H}$, Coultas L, Adams J, Kraft AS. The proteasome inhibitor bortezomib sensitizes cells to killing by death receptor ligand TRAIL via BH3-only proteins Bik and Bim. Mol Cancer Ther 2005; 4: 443-449.

9. Sayers TJ, Brooks AD, Koh CY, Ma W, Seki N, Raziuddin A et al. The proteasome inhibitor PS-341 sensitizes neoplastic cells to TRAIL-mediated apoptosis by reducing levels of c-FLIP. Blood 2003; 102: 303-310.

10. Ganten TM, Koschny R, Haas TL, Sykora J, Li-Weber M, Herzer K et al. Proteasome inhibition sensitizes hepatocellular carcinoma cells, but not human hepatocytes, to TRAll. Hepatology 2005; 42: 588-597.

11. Hallett WH, Ames E, Motarjemi M, Barao I, Shanker A, Tamang DL et al. Sensitization of tumor cells to NK cell-mediated killing by proteasome inhibition. J Immunol 2008; 180: 163-170

12. Galban S, Duckett CS. XIAP as a ubiquitin ligase in cellular signaling. Cell Death Differ 2010; 17: 54-60.

13. Vaux DL, Silke J. IAPs, RINGs and ubiquitylation. Nat Rev Mol Cell Biol 2005; 6: 287-297.

14. Rehm M, Dussmann H, Prehn JH. Real-time single cell analysis of Smac/DIABLO release during apoptosis. J Cell Biol 2003; 162: 1031-1043.

15. Fernandes-Alnemri T, Armstrong RC, Krebs J, Srinivasula SM, Wang L, Bullrich F et al. In vitro activation of CPP32 and Mch3 by Mch4, a novel human apoptotic cysteine protease containing two FADD-like domains. Proc Natl Acad Sci USA 1996; 93: 7464-7469.

16. Zhang XD, Gillespie SK, Hersey P. Staurosporine induces apoptosis of melanoma by both caspase-dependent and -independent apoptotic pathways. Mol Cancer Ther 2004; 3 : 187-197.

17. Rehm M, Dussmann H, Janicke RU, Tavare JM, Kogel D, Prehn JH. Single-cell fluorescence resonance energy transfer analysis demonstrates that caspase activation during apoptosis is a rapid process. Role of caspase-3. J Biol Chem 2002; 277: 24506-24514.

18. McStay GP, Salvesen GS, Green DR. Overlapping cleavage motif selectivity of caspases: implications for analysis of apoptotic pathways. Cell Death Differ 2008; 15: 322-331.
19. Rehm M, Huber HJ, Dussmann $\mathrm{H}$, Prehn JH. Systems analysis of effector caspase activation and its control by $X$-linked inhibitor of apoptosis protein. EMBO J 2006; 25: 4338-4349.

20. Hughes MA, Harper N, Butterworth M, Cain K, Cohen GM, MacFarlane M. Reconstitution of the death-inducing signaling complex reveals a substrate switch that determines CD95-mediated death or survival. Mol Cell 2009; 35: 265-279.

21. Pandey UB, Nie Z, Batlevi Y, McCray BA, Ritson GP, Nedelsky NB et al. HDAC6 rescues neurodegeneration and provides an essential link between autophagy and the UPS. Nature 2007; 447: 859-863.

22. Bell BD, Leverrier S, Weist BM, Newton RH, Arechiga AF, Luhrs KA et al. FADD and caspase-8 control the outcome of autophagic signaling in proliferating T cells. Proc Nat Acad Sci USA 2008; 105: 16677-16682.

23. Pankiv S, Clausen TH, Lamark T, Brech A, Bruun JA, Outzen H et al. p62/SQSTM1 binds directly to Atg8/LC3 to facilitate degradation of ubiquitinated protein aggregates by autophagy. J Biol Chem 2007; 282: 24131-24145.

24. Yu L, Alva A, Su H, Dutt P, Freundt E, Welsh $S$ et al. Regulation of an ATG7-beclin 1 program of autophagic cell death by caspase-8. Science 2004; 304: 1500-1502.

25. Ch'en IL, Beisner DR, Degterev A, Lynch C, Yuan J, Hoffmann A et al. Antigen-mediated T cell expansion regulated by parallel pathways of death. Proc Natl Acad Sci USA 2008; 105: 17463-17468.

26. Jost PJ, Grabow S, Gray D, McKenzie MD, Nachbur U, Huang DC et al. XIAP discriminates between type I and type II FAS-induced apoptosis. Nature 2009; 460: 1035-1039.

27. Fulda S, Wick W, Weller M, Debatin KM. Smac agonists sensitize for Apo2L/TRAIL- or anticancer drug-induced apoptosis and induce regression of malignant glioma in vivo. Nat Med 2002; 8: 808-815.

28. Miller CP, Ban K, Dujka ME, McConkey DJ, Munsell M, Palladino M et al. NPI-0052, a novel proteasome inhibitor, induces caspase-8 and ROS-dependent apoptosis alone and in combination with HDAC inhibitors in leukemia cells. Blood 2007; 110: 267-277.

29. Liu X, Yue P, Chen S, Hu L, Lonial S, Khuri FR et al. The proteasome inhibitor PS-341 (bortezomib) up-regulates DR5 expression leading to induction of apoptosis and enhancement of TRAIL-induced apoptosis despite up-regulation of C-FLIP and survivin expression in human NSCLC Cells. Cancer Res 2007; 67: 4981-4988.

30. Boatright KM, Renatus M, Scott FL, Sperandio S, Shin H, Pedersen IM et al. A unified model for apical caspase activation. Mol Cell 2003; 11: 529-541.

31. Arechiga AF, Bell BD, Leverrier S, Weist BM, Porter M, Wu Z et al. A Fas-associated death domain protein/caspase-8-signaling axis promotes S-phase entry and maintains $\mathrm{S} 6$ kinase activity in T cells responding to IL-2. J Immunol 2007; 179: 5291-5300.

32. Voortman J, Resende TP, Abou El Hassan MAI, Giaccone G, Kruyt FAE. TRAIL therapy in non-small cell lung cancer cells: sensitization to death receptor-mediated apoptosis by proteasome inhibitor bortezomib. Mol Cancer Therap 2007; 6: 2103-2112.

33. Caro-Maldonado A, Tait SW, Ramirez-Peinado S, Ricci JE, Fabregat I, Green DR et al. Glucose deprivation induces an atypical form of apoptosis mediated by caspase-8 in BaxBak-deficient cells. Cell Death Differ 2010.

34. Pepper C, Lin TT, Pratt G, Hewamana S, Brennan P, Hiller L et al. Mcl-1 expression has in vitro and in vivo significance in chronic lymphocytic leukemia and is associated with other poor prognostic markers. Blood 2008; 112: 3807-3817.

35. Zhao WL, Daneshpouy ME, Mounier N, Briere J, Leboeuf C, Plassa LF et al. Prognostic significance of bcl-xL gene expression and apoptotic cell counts in follicular lymphoma. Blood 2004; 103: 695-697.

36. Yang Q, Moran MS, Haffty BG. Bcl-2 expression predicts local relapse for early-stage breast cancer receiving conserving surgery and radiotherapy. Breast Cancer Res Treat 2009; 115: 343-348.

37. Vogler M, Dinsdale D, Dyer MJ, Cohen GM. Bcl-2 inhibitors: small molecules with a big impact on cancer therapy. Cell Death Differ 2009; 16: 360-367.

38. Wilson TR, McEwan M, McLaughlin K, Le Clorennec C, Allen WL, Fennell DA et al. Combined inhibition of FLIP and XIAP induces Bax-independent apoptosis in type II colorectal cancer cells. Oncogene 2009; 28: 63-72.

39. Hellwig CT, Kohler BF, Lehtivarjo AK, Dussmann H, Courtney MJ, Prehn JH et al Real time analysis of tumor necrosis factor-related apoptosis-inducing ligand/ cycloheximide-induced caspase activities during apoptosis initiation. J Biol Chem 2008; 283: 21676-21685.

40. Flanagan L, Sebastia J, Tuffy LP, Spring A, Lichawska A, Devocelle M et al. XIAP impairs Smac release from the mitochondria during apoptosis. Cell Death and Dis 2010; 1: e49.

Supplementary Information accompanies the paper on Cell Death and Differentiation website (http://www.nature.com/cdd) 